\title{
CRISIS Y CAPTURA: EL DESCONTENTO SOCIAL EN TIEMPOS DE PANDEMIA EN AMÉRICA LATINA Y EL CARIBE
}

Este documento esboza una propuesta de agendas de trabajo para promover el debate sobre cómo reconfigurar el pacto social por vías institucionales en América Latina y el Caribe, fortaleciendo así los sistemas democráticos de la región y hacer frente a privilegios. Estas cuestiones son esenciales en el contexto actual de pandemia y de crisis políticas. Cruzando datos estadísticos y con los estudios de caso de financiación de partidos (Perú), desarrollo turístico (República Dominicana), telecomunicaciones (Argentina) y acceso al agua (El Salvador), este documento establece la relación entre la captura de políticas públicas, desigualdad y desafección con la democracia. Los casos demuestran cómo el lobby, las puertas giratorias y las campañas mediáticas son los principales mecanismos con los que las élites ejercen influencia abusiva para alejar del interés general decisiones políticas cruciales. 
Recuadro 1. ¿De qué hablamos cuando decimos 'captura'?

2. Democracia en América Latina y el Caribe: de la desconfianza a su captura..................................4

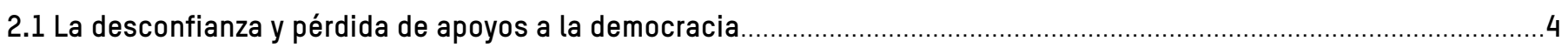

2.2 Desigualdad, captura y apoyo a la democracia

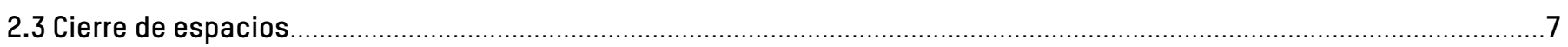

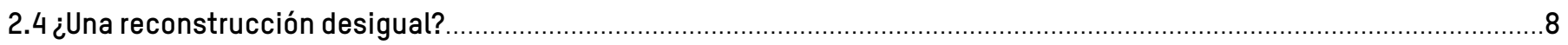

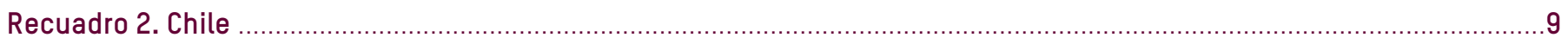

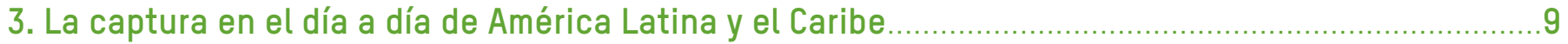

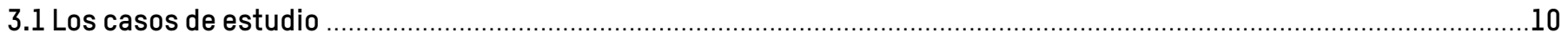

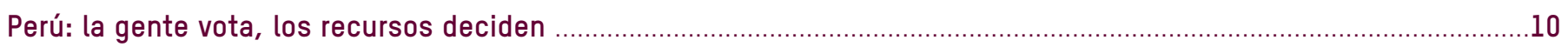

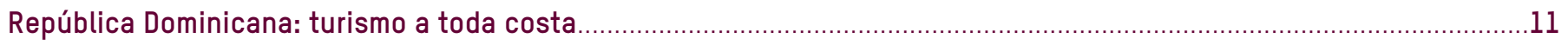

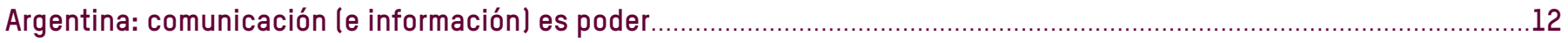

El Salvador: el derecho humano al agua

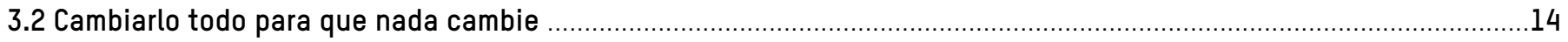

4. Una agenda de trabajo a futuro para reconfigurar el contrato social

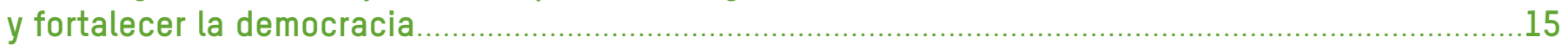

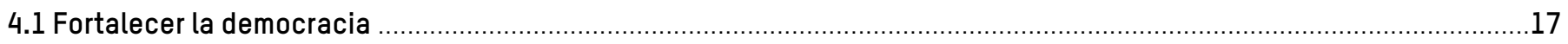

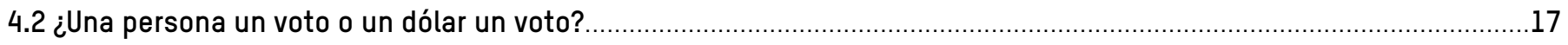

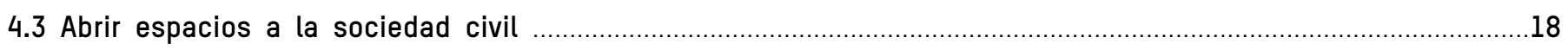

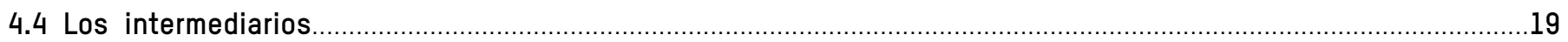

4.5 Una nueva cooperación internacional.

4.6 Sin impuestos no hay representación (ni servicios públicos de calidad) ........................................................20

4.7 Un nuevo paradigma económico y social: de bienes capturados a bienes públicos ...........................................20

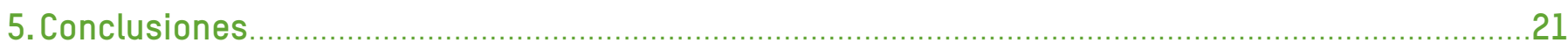

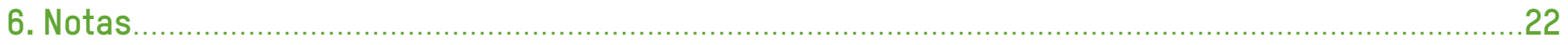




\section{INTRODUCCIÓN}

En América Latina y el Caribe (ALC), el estrecho vínculo que existe entre desigualdad, poder y dinero es central para entender cómo países con tanta riqueza generan a la vez pobreza y privilegios. El resultado es una elevada desigualdad que deslegitima el sistema democrático al permitir que aquellos que más poder tienen ejerzan una mayor influencia política. ${ }^{1}$ En una región donde el 10\% más rico concentra el 68\% de la riqueza es fácil apreciar la relación entre captura política y desigualdad (ver cuadro 1).2

Este documento sostiene que la captura es el mecanismo por el que se crean y perpetúan la desigualdad y los privilegios, además de una de las causas principales detrás del descontento social, la desafección democrática y las protestas que se suceden en casi todos los países de ALC. La captura es, a su vez, un síntoma de la debilidad de los estados. ${ }^{3}$ Para demostrarlo, se analiza la extensión del fenómeno de captura política en ALC y su impacto en la democracia y la desigualdad a partir de unos casos concretos de captura en los que diferentes políticas públicas han respondido más a los intereses de una élite que al interés general.

Se trata de casos anteriores a la pandemia que siguen siendo de gran actualidad. La pertinencia de prestar atención a las consecuencias de privilegiar intereses de ciertos grupos por encima de los de la mayoría ha aumentado, si cabe, al implementarse diferentes políticas de gran calado para hacer frente a la COVID-19 en ALC. No es casualidad que algunas élites se hayan podido vacunar antes que la mayoría de la población; o la presión de las grandes farmacéuticas a varios Gobiernos en la región. Tampoco lo es que las discusiones sobre los paquetes de rescate hayan avivado los debates sobre quién se beneficia de las políticas públicas y a quién sirve realmente el contrato social. La COVID-19 ha magnificado y evidenciado el costo de la captura en estados incapaces de hacer frente a la crisis sanitaria, económica y social.

El contexto actual ofrece una oportunidad para llevar a cabo una reconfiguración profunda de las relaciones de poder en la región; una reconfiguración que en los próximos meses será, con bastante probabilidad, el principal punto de colisión entre las élites y la ciudadanía. El resultado de dicha lucha puede desembocar en escenarios en los que las élites mantengan su poder, pero también en otros más positivos. El ejemplo de Chile (ver recuadro 2) es una muestra de que hay esperanza para las mejoras en el actual contexto.

En Latinoamérica, también se está produciendo desde hace años un cierre progresivo de los espacios para la sociedad civil, el activismo, el periodismo, etc. que se está agudizando con la pandemia y la respuesta de los Gobiernos. ${ }^{4}$ La protesta contra el statu quo, la disidencia social y el periodismo de investigación se restringen cada vez más mediante leyes que limitan el debate público y las libertades, al tiempo que se silencian voces alternativas, se instauran falsos debates en la opinión pública e, incluso, se militariza el espacio público. ${ }^{5}$ Este fenómeno de cierre está asociado con el poder de algunas élites, que buscan reprimir cualquier atisbo de protesta o disidencia y blindar así sus privilegios.

Con la crisis actual se ha abierto un período de cambios e inestabilidad en el que surgen debates sobre «nuevos» bienes públicos como la vacuna, la tecnología o la provisión de servicios públicos. En paralelo, la confianza en la democracia y en los partidos políticos se encuentra bajo mínimos; la ciudadanía ya no confía en que sean capaces de garantizar el acceso a dichos bienes.

La juventud está cada vez más desafecta del sistema y emergen, por un lado, nuevas voces desde movimientos sociales que apuestan por modelos alternativos basados en una democracia real, descentralizada, no institucionalizada e inclusiva; mientras que, por otro lado, hay sectores que reclaman políticas conservadoras y de orden.

Finalmente, este documento también quiere promover una reflexión sobre cuáles deben ser los cimientos a partir de los cuales reconfigurar los contratos sociales en ALC. En la cuarta sección, se plantean algunas propuestas que buscan contribuir a los debates sobre cómo fortalecer y volver a dotar de legitimidad a una democracia no asociada únicamente a una representación institucional, al acto electoral y a unos procesos participativos determinados, sino en relación con otros principios como el de igualdad y libertad. ${ }^{6}$ 


\section{¿De qué hablamos cuando decimos 'captura'?}

Cuando se habla de 'captura' es importante puntualizar a qué se hace referencia. ¿Captura del Estado, captura de la democracia, de la política, de ideas? Existen varias definiciones del concepto en diferentes ámbitos. ${ }^{7}$ La OCDE la define como «el proceso de alejar las decisiones de política pública del interés público hacia los intereses de un grupo o persona específica de forma repetida y consistente». Francisco Durand, desde la academia, la ve como «el proceso en el cual las élites económicas del poder, pese a la vigencia de las instituciones democráticas, utilizan una fuerza política abrumadora para proteger sus intereses económicos sobre el Estado». Para OXFAM, la captura es «el ejercicio de influencia abusiva por parte de una(s) élite(s) extractivals) - en favor de sus intereses y en detrimento del interés general-sobre el ciclo de políticas públicas y los organismos del Estado lu otros de alcance regional o internacionall con efectos potenciales en la democracia y la desigualdad». La captura de políticas públicas es, por lo tanto, el foco de atención de este documento. ${ }^{8}$

Hablar de políticas públicas centra el análisis en la importancia que tiene el diseño de las mismas. Más allá del objetivo que pueda tener una política determinada, lo central es conocer las relaciones de poder de una sociedad y si la implementación de la política alterará el statu quo, modificando el equilibrio de fuerzas de quién ostenta el poder de facto. ${ }^{9}$ En otras palabras, cómo se diseña una política y quién incide en el proceso de toma de decisiones determina quién se beneficia y quién sale perjudicado de la misma. Esto es lo que se conoce también como el estudio de la economía política.

Hay dos elementos más que se deben precisar. El primero hace referencia a quién captura. De algunas definiciones trasciende que son los grupos empresariales los principales agentes en este proceso. Sin embargo, dependiendo del contexto y de los recursos de poder estratégicos, hay otros actores que pueden ejercer la captura lgrupos armados, representantes políticos, etc.). Dicho esto, la relación con el poder económico siempre aparece de una u otra forma cuando se habla de captura.

El segundo elemento hace referencia a la distinción ente captura y corrupción. Según OXFAM, la corrupción es un mecanismo de la captura. La captura tiene un carácter estructural e incluye tanto elementos legales (la financiación de partidos) como ilegales (la corrupción misma). Mientras que en la corrupción existe siempre una transacción monetaria, en la captura no es así. Puede haber captura sin corrupción (p.ej., el uso legal del lobby) y viceversa (p.ej., un pago ilegal por un permiso burocrático). Finalmente, subrayar que la corrupción está al alcance de cualquier persona, mientras que la captura requiere del control de determinados recursos no siempre al alcance de todo el mundo.

\section{DEMOCRACIA EN AMÉRICA LATINA Y EL CARIBE: DE LA DESCONFIANZA A SU CAPTURA}

\subsection{La desconfianza y pérdida de apoyos a la democracia}

A día de hoy, se calcula que solo un $8,4 \%$ de la población mundial vive en democracias plenas; ${ }^{10}$ y alrededor de unos 1.500 millones de personas viven en países en los que el descontento con la democracia es generalizado. ${ }^{11}$ Esta desazón es incluso mayor si nos centramos en la generación millennial (nacidos entre 1980-1996), la menos satisfecha. ${ }^{12}$

Por regiones, el mayor aumento de la insatisfacción se ha producido en Europa del Sur, principalmente en España. Sin embargo, si hay una región en la que este descontento y desconfianza sea más marcado en los 5 últimos años, esta es ALC. Tanto es así, que se habla de la década pasada como «la década de la pérdida de confianza en la democracia». ${ }^{13}$

En consecuencia, la satisfacción con el desempeño del sistema democrático y la confianza en sus diferentes instituciones es cada vez menor. Todos los indicadores muestran una tendencia negativa en la última década (ver gráfico 1). Se ha llegado al caso extremo de que solo tres de cada diez personas en ALC confían en los partidos políticos. ${ }^{14}$ Pese a ello, continúa habiendo más personas que apoyan la democracia como sistema de gobierno que personas que no lo hacen. 
Gráfico 1: Apoyo a la democracia y confianza en varias instituciones ALC (2010-2019)

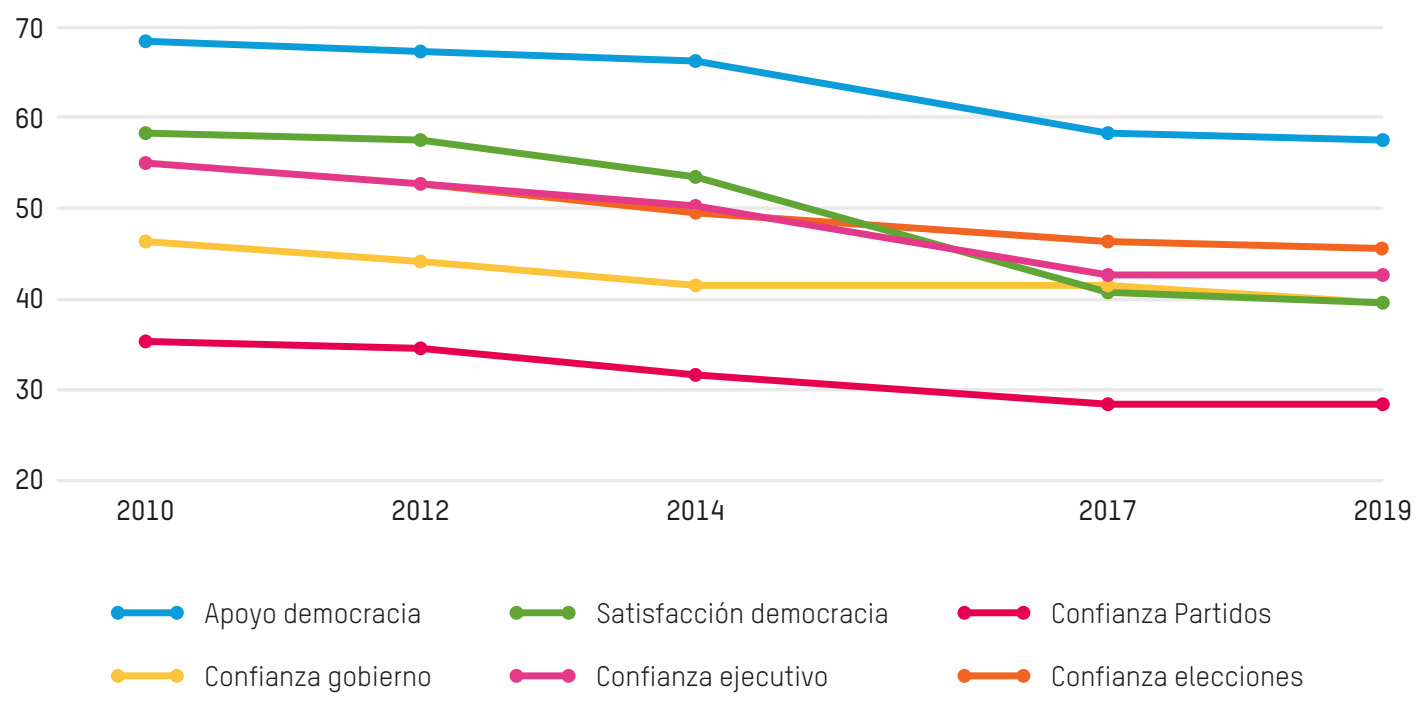

Fuente: elaboración propia a partir de datos del AmericasBarometer 2019.

A los datos anteriores se unen una media de un $73 \%$ de personas que perciben que se gobierna en favor de una minoría len Brasil, Colombia, Costa Rica, Perú y Paraguay, donde este porcentaje es de casi un $90 \%$ (15; $^{15}$ un 57\% que cree que su gobierno no hace suficiente contra la corrupción y un $65 \%$ que piensa que se gobierna exclusivamente para intereses privados. ${ }^{16}$

Estas estadísticas son previas a la llegada de la pandemia a la región. No se sabe con exactitud cuál será el impacto de la misma en la confianza en la democracia, pero la deficiente respuesta sanitaria unida a los problemas y escándalos ligados al acceso a las vacunas podrían añadir más dudas acerca de a quién sirve la democracia realmente, llegándose a legitimar derivas autoritarias. En este sentido, algunas encuestas respecto a la aceptación presidencial en la región, de finales de 2020, muestran como solo Uruguay aprobaba a su jefe de Estado. ${ }^{17}$

\subsection{Desigualdad, ${ }^{18}$ captura y apoyo a la democracia}

Los análisis anteriores abren el debate sobre cuál podría ser la causa principal detrás de la tendencia a una mayor desafección y un menor apoyo a la democracia. ${ }^{19}$ Una primera posibilidad podría ser la alta vulnerabilidad que condena a casi un 40\% de la población en ALC a vivir con entre 5,5 y 13 dólares diarios, o las mayores aspiraciones de algunos segmentos de la población que se han visto frustradas. Sin embargo, todos estos elementos están ligados de forma clara con la desigualdad.

La elevada desigualdad de la región juega, sin lugar a dudas, un papel determinante en todo este proceso de desafección. En este sentido, está demostrado que:

- Las democracias más sólidas redistribuyen más y ofrecen mayor protección social.20

- Una mayor desigualdad reduce la movilidad social. ${ }^{21}$

- El potencial para reducir la desigualdad es menor sin democracia. ${ }^{22}$

En el caso de Latinoamérica, se observa una correlación negativa ${ }^{23}$ entre desigualdad y apoyo a la democracia (ver gráfico 2), al cruzar datos de 17 países sobre desigualdad y apoyo medio a la democracia. ${ }^{24}$ Por lo tanto, la desigualdad -ligada a una escasa movilidad intergeneracional- es un factor relevante para entender el menor apoyo a la democracia en la región.

Cada vez es mayor la acumulación de ingreso y riqueza en menos manos, así como el contrastado aumento del GINI debido al impacto de la pandemia. Sin embargo, los datos también muestran en los últimos años un estancamiento del mismo índice en varios países de la región, así como dan cuenta del hecho de que no necesariamente donde mayor es la desigualdad más insatisfacción se tiene. ${ }^{25}$ Por lo tanto, pese a ser un elemento crucial para entender la pérdida de apoyo a la democracia, la desigualdad no es el único factor. 
Gráfico 2: Relación entre GINI de ingreso y apoyo a la democracia (2013-2019)

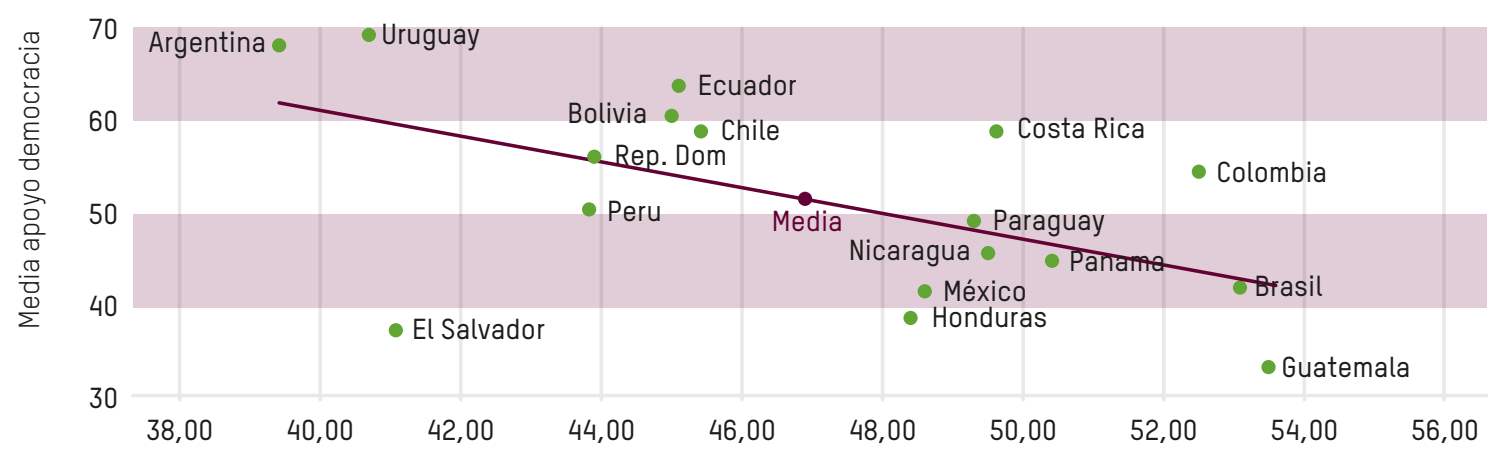

Media GINI de inareso

Fuente: CEPAL (2021) y Latinobarómetro (2018)

El otro elemento que aquí se considera central para entender la caída en el apoyo a la democracia es la captura política y la prevalencia de los intereses privados de determinados grupos de poder en la política (ver gráfico 3). ${ }^{26}$

Gráfico 3: Relación entre apoyo a democracia e igualdad de poder político por posición socioeconómica $(2015-2018)^{27}$

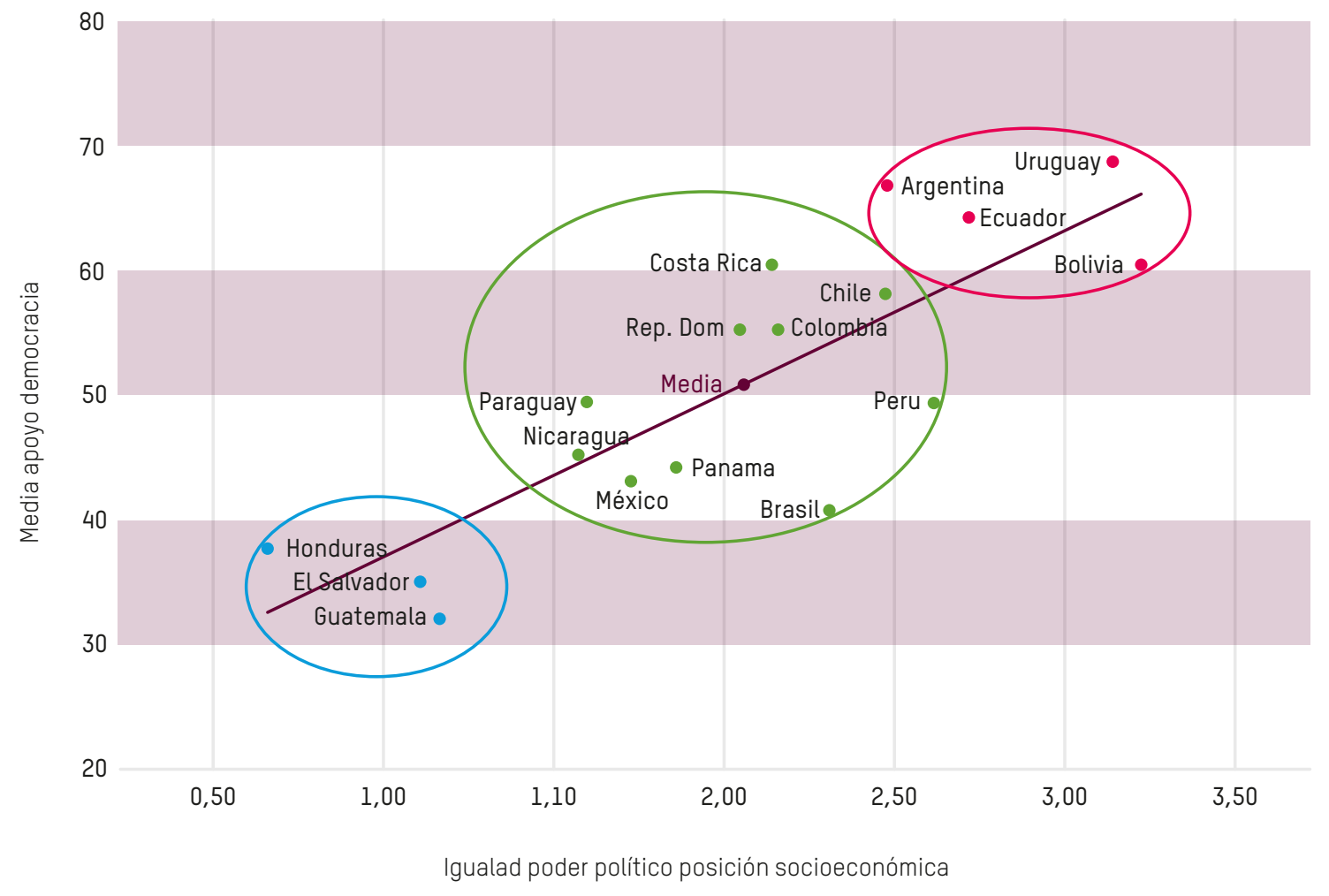

Fuente: Social Progress Index (2021)

Este gráfico muestra cómo, de forma similar a como ocurre con la desigualdad, a mayor poder político por parte de los grupos socioeconómicos más ricos, más se reduce el apoyo a la democracia. En este caso, la correlación positiva permite apreciar tres grupos de países. En primer lugar, los países centroamericanos (círculo azul) donde esta concentración de poder político es más pronunciada ${ }^{28}$ y, a su vez, hay un apoyo a la democracia muy bajo. En segundo lugar, tenemos los paí- 
ses con más igualdad en el poder político - destacando Bolivia y Uruguay - y un apoyo alto a la democracia (círculo rojo). Finalmente, en el grupo intermedio encontramos a Chile, Costa Rica, Perú, Brasil (pese a su bajo apoyo a la democracia) 0 Panamá, entre otros (círculo verde).

A pesar de que tanto la correlación entre desigualdad y apoyo a la democracia y entre igualdad de poder político y apoyo a la democracia puedan parecer obvias, son dos elementos estructurales de la región ALC que, al cruzarse entre ellos, dejan un panorama de «semi-ruptura» del contrato social. Aunque los datos estadísticos muestran una reducción de la desigualdad medida en términos de GINI en los últimos años, el poder político por posición socioeconómica sí que se ha mantenido altamente concentrado, salvo en raras excepciones. Esto es, sin lugar a dudas, una de las principales motivaciones de gran parte de las protestas de los últimos años en la región. ${ }^{29}$

Los gráficos y análisis anteriores sugieren una pregunta fundamental: ¿qué se entiende por democracia? Según varios estudios en la región, la democracia se asocia principalmente a los conceptos de libertad y derecho a decidir, y se identifican los principales beneficios de vivir en una democracia con una mejor distribución del ingreso y la justicia social. ${ }^{30}$ En sociedades en los que tanto la desigualdad como la captura política se han convertido en fenómenos estructurales, los principios legitimadores de la democracia se ven erosionados. Se vive en una democracia formal en la que se han otorgado derechos varios, pero la «maquinaria del poder» ha quedado intacta. De ahí la persistencia de los privilegios y de la desigualdad.

\subsection{Cierre de espacios}

ALC es una de las regiones del mundo en la que más se ha cerrado el espacio cívico en los últimos años al irse limitando progresivamente sus tres componentes esenciales: libertad de reunión, libertad de asociación y libertad de expresión. ${ }^{31}$ Así lo constatan tanto múltiples informes como, principalmente, los testimonios de todos los países en relación a cómo las disidencias se silencian, se reprimen y, en algunos casos, hasta se eliminan mediante el asesinato. ${ }^{32}$ Las restricciones de uso del espacio público por la pandemia de la COVID-19 han acentuado más si cabe este fenómeno de cierre de espacios. ${ }^{33}$

Actualmente la región está sufriendo un retroceso generalizado del espacio cívico. Todos los países -salvo Uruguay, que lo tiene abierto - tienen el espacio reducido en mayor o menor medida: obstruido (la mayoría), reprimido o cerrado (ver gráfico 4). Este último año se han producido retrocesos en Costa Rica (antes abierto), Chile y Ecuador. ${ }^{34}$

Después de un 2019 marcado por una gran agitación social en la región -con protestas extendidas en Chile, Ecuador y Colombia-, el cierre del espacio público y las restricciones de movilidad propiciaron una cierta calma social que tanto movimientos sociales como periodistas y analistas consideraron como beneficiosas para los intereses de las élites contra las que se protestaba. ${ }^{35}$ Sin embargo, en la segunda mitad de 2020 la protesta se ha mantenido -y en algunos casos aumentado, como en Perú o Guatemala-, mientras que se presencia en los más recientes sucesos en Colombia una escalada de la violencia estatal. En todos estos países, la crisis de representatividad, el poder de las élites y la frustración con el statu quo lanzaron a la calle a gran parte de la ciudadanía en lo que se ha bautizado como La rebelión contra las élites en América Latina. ${ }^{36}$

El espacio cívico es la base de cualquier sociedad democrática abierta. Es en el espacio cívico donde se lleva a cabo la oposición y la protesta, donde se construyen alternativas que, en ocasiones, pueden poner en jaque al poder formal e informal de una sociedad. Es también el lugar donde la ciudadanía puede convertirse en un agente de cambio real. ${ }^{37}$ De ahí, la importancia estratégica que tiene su control para las élites.

Las élites pueden usar sus recursos de poder para tener un acceso privilegiado al poder político y económico, para

\section{Gráfico 4: Países ALC y estado de su espacio cívico en $2020(\%)$}

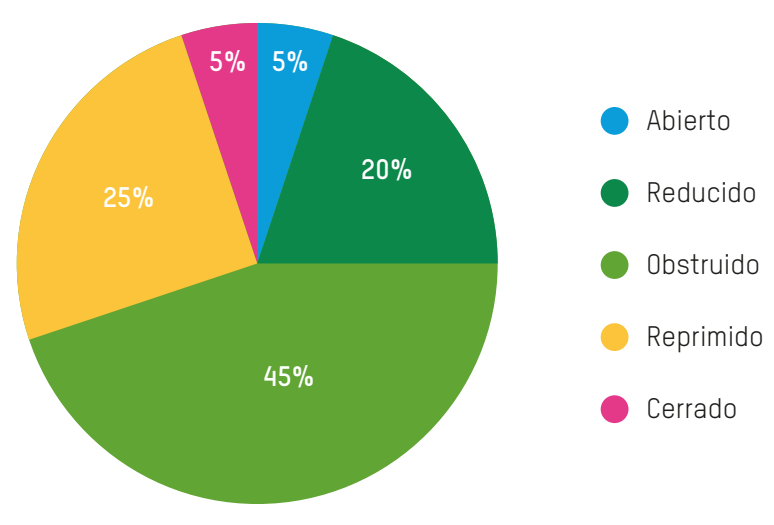

Fuente: CIVICUS Civil Society Report 2020

conseguir limitar la legalidad de la disidencia y la protesta e, incluso, militarizar la calle como está sucediendo en la mayoría de países. Leyes de medios, limitaciones del uso del espacio público, control de redes sociales y ataques a personas, periodistas u organizaciones forman parte de los mecanismos de los que hacen uso. ${ }^{38}$ 
La crisis de la COVID-19 ha puesto de manifiesto la fuerza con la que se ha trabajado para controlar el espacio cívico y hasta qué punto un contexto favorable puede llegar a instrumentalizarse para dicho fin. ${ }^{39}$ En sociedades con espacios cívicos ya de por sí poco abiertos y un poder político altamente concentrado, el contexto pandémico ha representado una gran oportunidad para aquellos con más conexiones con el poder. Existen excepciones y se han dado avances en algunos terrenos, liderados por la lucha social (por ejemplo, en Argentina con la Ley de Interrupción Voluntaria del Embarazo de 2020). No obstante, el contexto no es muy propicio para avanzar hacia una apertura de espacios.

En un momento de tanta relevancia como el actual, en el que no solo se debate sobre la salida de la pandemia sino también cómo reconfigurar el contrato social, tener un espacio cívico abierto es fundamental para que la ciudadanía pueda hacer oír su voz más allá del voto. De lo contrario, decisiones cruciales podrían ser consensuadas en procesos políticamente desiguales, cuestiones como qué empresas y sectores serán ayudados, qué podrán exigir los Gobiernos a cambio de los rescates y, en definitiva, qué reglas del juego y prioridades se establecerán. Es por ello que la defensa del espacio cívico es cada vez más estratégica.

\section{4 ¿Una reconstrucción desigual?}

La COVID-19 ha evidenciado su impacto desigual en la población, así como la desigual capacidad que tienen diferentes actores para influenciar en la toma de decisiones políticas. Las élites y los grupos de poder se han movilizado -en algunos casos, con éxito- para hacer prevalecer sus intereses en el diseño e implementación de paquetes de ayudas, reformas, normas de contratación, etc. ${ }^{40}$ Es el caso de la República Dominicana con el nuevo Plan de Recuperación Responsable de Turismo, en el que se privilegia los grandes grupos hoteleros al limitar los requerimientos sanitarios a los turistas extranjeros. ${ }^{41}$ También ha ocurrido con la influencia y alta coordinación entre las cámaras empresariales y los gobiernos de Honduras y Guatemala sobre reformas fiscales regresivas. ${ }^{42}$ Igualmente, en Perú se ha concentrado la ayuda, con cuatro bancos controlando alrededor del 90\% de la asignación de los fondos del programa de recuperación económica Reactive Perú.43

Esta situación también se está dando en Europa y en EE UU, lo cual demuestra la importancia de un contexto como el actual y las oportunidades que brinda a grupos bien conectados o con recursos para acceder privilegiadamente a la toma de decisiones. ${ }^{44}$ Las grandes corporaciones están gastando más que nunca en actividades de lobby para aumentar su influencia, mejorar su acceso a la toma de decisiones, conseguir una reducción de su carga fiscal, rebajar la protección de los trabajadores, etc..$^{45}$

Bajo la crisis pandémica global, poder vacunarse es seguramente la mayor preocupación para regresar a la vida normal. El acceso a la vacuna está evidenciando de nuevo los privilegios de los grupos de poder. Sus miembros están consiguiendo vacunarse, saltándose todos los protocolos y procesos administrativos. Estos escándalos generan debates sobre a quién sirve realmente la democracia.

En paralelo al acceso a las vacunas, emerge otro debate sobre la concentración de poder en el sector farmacéutico. Un sector en el que poco más de quince multinacionales controlan la mitad del comercio y producción global de medicamentos, ${ }^{46}$ protegidas por normas internacionales (como las patentes vía Acuerdos Comerciales) que refuerzan su poder e impiden que la vacuna sea un bien público global. La situación evidencia además su desmedido poder de negociación y capacidad para establecer las reglas del juego a Gobiernos de todo el mundo. En países como los de ALC esta estrategia negociadora ha sido revelada y ha empujado a algunos gobiernos a prescindir de las vacunas provenientes de dichas multinacionales, y utilizar en cambio las desarrolladas por China o Rusia. ${ }^{47}$

Todo lo anterior plantea la duda de si los gobiernos tienen poder y legitimidad suficientes para dar respuesta al desafío de la protección sanitaria y el acceso a las vacunas de la ciudadanía sin que los intereses de las élites influyan en la toma de decisiones. El reto es convertir este desafío en un ejercicio de fortalecimiento de la democracia. Para ello se requiere de normas, políticas públicas y transparencia de los Gobiernos en sus contratos y planes, así como de cooperación internacional para que las compañías farmacéuticas compartan su tecnología y liberen patentes con el fin de posibilitar que las vacunas puedan administrarse en la región a bajo costo. 


\section{Chile}

El caso chileno - con el proceso que ha llevado a la aprobación del referéndum y a las recientes elecciones a la Convención Constituyente- es un caso paradigmático de cómo con mecanismos institucionales democráticos es posible encontrar espacios para contrarrestar unos privilegios largamente arraigados en una sociedad. En este caso, la vía adoptada es la reforma de la Constitución.

La actual Constitución chilena mantiene en esencia las bases del régimen pinochetista y los privilegios de la élites pese a que modificó el sistema de dictatorial a democrático; además, fue aprobada en un momento en el que la sociedad chilena demandaba una mayor transición democrática (1980).48 A pesar de la conquista de varios derechos económicos, políticos y sociales, la organización del poder en el país ha continuado siendo fundamentalmente la misma, controlada por un reducido grupo de élites. ${ }^{49}$ Este grupo ha ido reproduciéndose en los mismos espacios de encuentro - escuelas, universidades, bancadas políticas, sectores económicos y financieros- y vetando diferentes propuestas que buscaban reducir privilegios y desigualdades. ${ }^{50}$

Tras años de implementación de políticas neoliberales, la falta de reconfiguración del poder ha hecho que, entre 2000 y 2017, la diferencia entre el ingreso que recibe el 10\% más rico y el habitante medio haya crecido un $45 \%$, que un $40 \%$ de los y las pensionistas reciban un ingreso por debajo de la línea de la pobreza, y que las empresas mineras no paguen royalties por la extracción del cobre. ${ }^{11}$ Esta situación se desbordó en 2019 con el «estallido social» por el aumento de la tasa del metro, al ponerse en marcha un movimiento de reforma amplio. Este proceso reformista culminó en octubre de 2020 con el voto mayoritario en favor de una reforma constitucional, a pesar de una participación baja $(50.95 \%)$.

En dicha votación también participaron ciudadanos contrarios a un cambio del statu quo. Como muestra evidente, los tres barrios más pudientes de Santiago de Chile (Vitacura, Lo Barnechea y Las Condes) - donde se concentra gran parte de las élites chilenas - votaron en contra de una reforma que alteraba un marco que les había beneficiado durante décadas; frente a la aceptación en el resto de comunas de esa ciudad, incluidas Providencia o La Reina, de clase media. Así, la mayoría de la sociedad, incluyendo clases medias emergentes y algunas élites políticas del país, entendieron el proceso como una oportunidad para redefinir las reglas del juego o, cuanto menos, para conversar de forma amplia con toda la sociedad sobre el contrato social. ${ }^{52}$

Este proceso de debate social y político sobre el futuro del país entre todos los segmentos de la sociedad chilena es un caso único de lo que se podría llamar «contracaptura». Es decir, cómo la ciudadanía ha conseguido la capacidad política para dar un vuelco a una situación de privilegios y, como mínimo, poder discutir alternativas a la misma por la vía institucional, garantizando la igualdad de género y de los pueblos originarios.

\section{LA CAPTURA EN EL DÍA A DÍA DE AMÉRICA LATINA Y EL CARIBE}

Esta sección presenta los cuatro casos de captura política (intento de captura en el caso de El Salvador) en ALC que han sido desarrollados por OXFAM en alianza con actores de la sociedad civil y la academia. Los casos no se detallan en su totalidad ya que aquí solo se quiere resaltar los elementos más destacados, pero sirven con creces para mostrar el alcance del fenómeno y su impacto en la región. Aunque tratan sobre sectores diferentes, todos ellos tienen un efecto directo o indirecto en la desigualdad y la democracia. Su elección responde a tres motivos: (i) son sobre sectores que conectan con la actualidad de la región; (ii) son centrales por su impacto en la reducción de brechas o generación de bienestar; y (iii) son estratégicos para abordar el debate de la reconfiguración del contrato social en la región.

Algunos de estos estudios forman parte de las segundas becas de investigación sobre captura en ALC organizadas por CLACSO, OXFAM y la Fundación FES. ${ }^{53}$ Estas becas cubren diferentes países de ALC y utilizan como marco metodológico de referencia el documento El fenómeno de la captura: guía de análisis de la captura de políticas públicas y su efecto sobre la desigualdad de Oxfam Intermon. Así, estas investigaciones se centran en hilar las respuestas a cinco preguntas para desarrollar los casos (ver cuadro 1): 
Figura 1: Fases y preguntas de investigación para el análisis de captura de políticas públicas
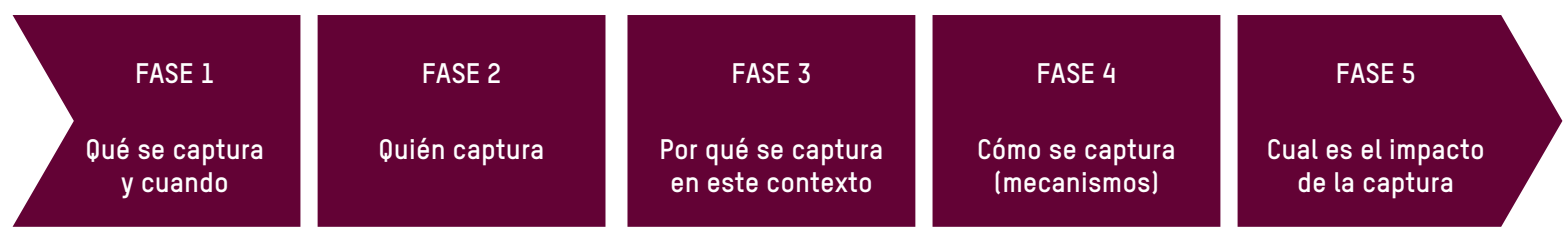

Fuente: elaboración propia

\subsection{Los casos de estudio}

Perú: la gente vota, los recursos deciden ${ }^{54}$

\begin{tabular}{|c|c|c|c|}
\hline Temática & Qué se captura & Cómo se captura & Impacto \\
\hline $\begin{array}{l}\text { Financiación } \\
\text { de la democracia }\end{array}$ & $\begin{array}{l}\text { Elecciones } \\
\text { presidenciales } \\
2011 \text { y 2016; } \\
\text { y elecciones } \\
\text { de diputados/as. }\end{array}$ & $\begin{array}{l}\text { Donaciones a } \\
\text { partidos } \\
\text { Campaña } \\
\text { mediática } \\
\text { Uso de recursos } \\
\text { privados }\end{array}$ & $\begin{array}{l}\text {-Mayor peso del dinero en la política. } \\
\text { - Inicio de cadena de favores que se } \\
\text { traduce en captura de políticas } \\
\text { (incluso del Estado). } \\
\text {-Deslegitimización del funcionamiento } \\
\text { de la democracia. }\end{array}$ \\
\hline
\end{tabular}

El dinero es el recurso de poder más común en nuestras sociedades. Permite que intereses particulares influyan en la toma de decisiones políticas. Se trata de una relación compleja: el dinero es esencial para la política - principalmente en la financiación de las campañas electorales - y la política es esencial para preservar y expandir los intereses y privilegios de los donantes, sobre todo, de los grandes donantes. Esta es una de las principales conclusiones del trabajo sobre la financiación de las campañas presidenciales en Perú de 2011 y 2016.

Partiendo de preguntas como ¿de dónde procede el dinero de las campañas y quién lo canaliza? o ¿qué deudas genera y cómo se pagan?, el estudio analiza dos contiendas electorales para ver el peso de las élites y los grupos de poder en la política. Las elecciones presidenciales de 2011 y 2016, dos momentos políticos diferentes, muestran un elemento común: el poder que tienen los grandes donantes y los grupos empresariales para financiar las campañas a la mayoría de candidatos, ya sea de forma legal o ilegal, sin importar su supuesta posición ideológica o propuesta programática. El estudio también muestra cómo estas élites invierten más recursos en las segundas vueltas de las elecciones cuando existe la posibilidad de que gane algún/a candidato/a que puede poner en riesgo sus intereses. ${ }^{55}$

Este estudio es novedoso ya que la financiación de la política sí que se ha estudiado en profundidad cuando proviene del crimen organizado, pero pocas veces se han tenido en cuenta los aportes monetarios y en especie provenientes de grandes grupos empresariales. Esto último, aunque se tiende a obviar en las discusiones más oficiales, se ha hecho más evidente tras el escándalo de Odebrecht que ha salpicado toda la región. ${ }^{56}$ Sin embargo, cada vez hay más estudios apuntando a cómo el dinero legal/ilegal de grandes grupos es la puerta de entrada de la captura política.

Este último elemento es una de las hipótesis que el estudio plantea. Cómo a través de la financiación electoral se abren las posibilidades de captura vía lobby y puertas giratorias que permiten devolver los favores a los grandes financiadores, manteniendo y reforzando sus intereses. Esto pone en entredicho la capacidad de cambio que pueden tener procesos de reforma institucional y regulaciones sobre el uso del dinero en democracia. Es decir, la financiación de la política es el mayor mecanismo de captura que existe, ya que permite ponerla en marcha y establecer las reglas que más benefician a dichos donantes. El caso del Perú está repleto de ejemplos sobre ello.

Al hablar de financiación de campañas por parte de élites y grupos de poder, el estudio demuestra que no solo se trata de aportes monetarios. Los grandes actores tienen también a su disposición medios de comunicación, abogados, infraestructuras, propiedades, etc. que ponen al servicio de los candidatos para que hagan uso de ellos. Esta capacidad ha llevado a algunos miembros de dichos grupos de poder a formar sus propias plataformas electorales. Tal es el caso de Pedro Pablo Kuczynski en Perú quien, de la nada, creó su propio partido PPK (Peruanos Por el Kambio; unas siglas que son, también, las suyas). El propio Kuczinsky fue el primer gran financiador de su campaña y supuesto receptor de aportes de Odebrecht. ${ }^{57}$ 
Las dos elecciones analizadas muestran cómo el dinero privado predomina en la financiación electoral a través de grandes donaciones (declaradas y no declaradas) que se realizan en los momentos críticos de campaña. Estas donaciones van a todos los candidatos, pero se acentúan en aquellos que defienden mejor los intereses de las élites. En el caso de las elecciones de 2011, el $80 \%$ de la financiación de Fuerza Popular 2011 provino de dichas fuentes. ${ }^{58}$ Todos los partidos procuran camuflar los fondos que reciben de forma no declarada con diferentes acciones, como por ejemplo la organización de cocktails. Estos fondos de grandes grupos generan una «deuda» que esperan que se les retorne vía políticas públicas que les beneficien o que, por lo menos, no pongan en riesgo sus intereses.

\section{República Dominicana: turismo a toda costa ${ }^{59}$}

\begin{tabular}{|c|c|c|c|}
\hline Temática & Qué se captura & Cómo se captura & Impacto \\
\hline Turismo & $\begin{array}{l}\text { Ley 158-01 } \\
\text { de Fomento } \\
\text { al Desarrollo } \\
\text { Turístico y cinco } \\
\text { modificaciones } \\
\text { posteriores (Ley } \\
\text { 184-02, 318-04, } \\
\text { Decreto 835-08, } \\
\text { Ley 253-12 y } \\
\text { 195-13). }\end{array}$ & $\begin{array}{l}\text { Velo técnico } \\
\text { Campaña } \\
\text { mediática } \\
\text { Puertas giratorias } \\
\text { Lobby } \\
\text { Procedimientos } \\
\text { legislativos } \\
\text { extraordinarios } \\
\text { (Madrugones) }\end{array}$ & $\begin{array}{l}\text {-Fuga de recursos hacia los países } \\
\text { emisores de turismo. } \\
\text {-Sistema tributario regresivo y poco } \\
\text { eficiente que dificulta realizar } \\
\text { políticas distributivas vía política } \\
\text { fiscal. } \\
\text {-Modelo de desarrollo focalizado } \\
\text { en grandes grupos hoteleros e } \\
\text { inmobiliarios con bajo efecto } \\
\text { distributivo. } \\
\text {-Desarrollo desigual de las diferentes } \\
\text { regiones del país. } \\
\text {-Abandono de sectores económicos } \\
\text { como la agricultura. } \\
\text {-Salarios promedio por debajo de la } \\
\text { media del país. } \\
\text {-Gestión mercantil del agua } \\
\text { que dificulta el acceso a las } \\
\text { comunidades. } \\
\text {-Sobreexplotación de recursos } \\
\text { naturales. }\end{array}$ \\
\hline
\end{tabular}

Este estudio aborda la captura de la Ley 158-01 de Fomento al Desarrollo Turístico y sus cinco posteriores modificaciones en República Dominicana. Dicha Ley estableció varias ampliaciones del alcance geográfico y las exenciones fiscales para el sector turístico en uno de los países del mundo que más incentivos de este tipo ofrece. ${ }^{60}$ Es notorio que el turismo es fundamental para la economía dominicana, pues representa un $25 \%$ del PIB del país y un $35 \%$ del empleo total. ${ }^{61}$

Los complejos hoteleros y las zonas de desarrollo económico ligadas al sector turístico están ubicadas en zonas específicas del país que son propiedad de un reducido número de grupos hoteleros de capital internacional -élites transnacionales de origen principalmente español- con gran poder también sobre los flujos turísticos, recursos financieros y comerciales del sector a nivel global. ${ }^{62}$ La posición asimétrica del gobierno dominicano ante estos grupos de poder es evidente dada la importancia y la dependencia de esta actividad económica del país, desde los años noventa, que reporta casi 8.000 millones de dólares de ingresos anuales.

La importancia estratégica del turismo para el país, junto al reducido número de actores dentro del sector y su alcance transnacional, ha acrecentado aún más el poder que las élites del sector tienen para hacer prevalecer sus intereses en las políticas públicas que les afectan. Por ejemplo, las exenciones tributarias, mal llamadas «incentivos fiscales», de las que gozan y que se amplían (en años, alcance geográfico y actividades) con la Ley en cuestión y sus posteriores reformas. Estas exenciones han supuesto dejar de ingresar 820 millones de dólares entre 2009 y 2018, según datos del Ministerio de Hacienda.

El estudio de este caso muestra el entendimiento y la complicidad entre los grupos de poder económico y el Estado para promover reformas a favor de intereses empresariales. De esta forma, por ejemplo, la última modificación a la Ley 158-01 incluye, entre otras, una ampliación del período de las exenciones de 10 a 15 años. 
En este caso, las élites utilizan varios mecanismos para permear todo el ciclo de política pública. Principalmente las puertas giratorias, las campañas mediáticas de desinformación y los procedimientos legislativos extraordinarios (los llamados madrugones). Más allá de los efectos directos de las exenciones en la recaudación fiscal, la captura perpetúa un modelo de desarrollo basado en la explotación de recursos naturales, precariza el trabajo dentro del sector turístico y privilegia los intereses de grupos internacionales por encima del desarrollo local.

\section{Argentina: comunicación (e información) es poder ${ }^{63}$}

\begin{tabular}{|c|c|c|c|}
\hline Temática & Qué se captura & Cómo se captura & Impacto \\
\hline Telecomunicaciones & $\begin{array}{l}\text { Captura de la Ley } \\
\text { de Servicios de } \\
\text { Comunicación } \\
\text { Audiovisual }\end{array}$ & $\begin{array}{l}\text { Campaña mediática } \\
\text { Lobby nacional / } \\
\text { internacional } \\
\text { Judicialización } \\
\text { Puertas giratorias }\end{array}$ & $\begin{array}{l}\text {-Pluralidad de medios alternativos } \\
\text { afectada. } \\
\text {-Licencias para medios comunitarios } \\
\text { limitadas. } \\
\text {-Las comunidades no tienen espacio } \\
\text { mediático ante la preponderancia del } \\
\text { mercado. } \\
\text {-Concentración mediática. }\end{array}$ \\
\hline
\end{tabular}

Un sector que despierta gran interés por su relevancia política es el de las telecomunicaciones. No en vano controlar cómo se genera la opinión pública otorga un gran poder. El caso de Argentina con la Ley de Servicios de Comunicación Audiovisual (LSCA) de 2009 es paradigmático de las luchas entre las élites políticas y mediáticas/económicas, de uno y otro lado del espectro ideológico, para capturar una ley cuya esencia era desconcentrar la propiedad de los medios en Argentina. La Ley en cuestión permitía la apertura y concesión de licencias a radios y medios de comunicación comunitarios, así como la participación de nuevos actores en las instituciones que regulan los medios en el país.

La LSCA venía a sustituir la Ley 22.285 de 1980 -aprobada bajo la dictadura cívico-militar - que vetaba las licencias audiovisuales a entidades sin ánimo de lucro. Se aprobó durante el gobierno kichnerista bajo una férrea oposición de las élites empresariales y políticas vinculadas. Una vez se produce el cambio de gobierno, con la victoria de Mauricio Macri en 2015, una de las primeras medidas aprobadas fue precisamente una modificación de la LSCA a medida del grupo mediático dominante.

Tras varias disputas entre élites de diferente color político - todas relacionadas a su vez con diferentes grupos mediáticos-, se generó un espacio para promover la Ley en 2009. Es en este momento cuando se produce un primer intento por parte de la oposición de capturar el proceso de discusión de la ley y el debate en la opinión pública. Para ello, la campaña mediática y la judicialización son los mecanismos centrales que se utilizan para impulsar en el debate público una contraposición entre "libertad de expresión individual/empresarial" y "control estatal". Esta contraposición entre "libertad individual" y "derechos humanos y sociales" es uno de los elementos centrales de este caso de captura que va más allá de la política pública y entra de lleno en el terreno ideológico y de valores.

Al aprobarse la Ley en 2009, se consigue finalizar un proceso de «contracaptura» en el sentido de que los intereses sociales pasan a ser centrales en la temática de las telecomunicaciones. Grupos sociales organizados durante años tejen una alianza con determinadas élites políticas para conseguir su aprobación. Sin embargo, una vez cambia el gobierno, la LSCA se deroga de urgencia y los actores sociales son expulsados de los entes reguladores en favor de las élites empresariales. Ello produce una gran concentración mediática y un incremento de la desigualdad en el acceso a los medios.

Más allá de mecanismos clásicos de captura - como pueden ser las puertas giratorias, la judicialización o el lobby-, en este caso es relevante el uso que se hace de la campaña mediática para conseguir una captura de las ideas o las narrativas. De esta forma, el poder que unas determinadas élites tienen sobre los grandes grupos mediáticos del país propicia la implantación en la sociedad de un debate ideológico sobre la Ley. Se confrontan así una visión político-ideológica que prioriza la «libertad de expresión individual/empresarial» (gobierno de Mauricio Macri de corte neoliberal) con otra del «derecho humano y social a la comunicación y la información» (gobierno kichnerista de corte social). 
El Salvador: el derecho humano al agua

\begin{tabular}{|c|c|c|c|}
\hline Temática & Qué se captura & Cómo se captura & Impacto \\
\hline Gestión del agua & $\begin{array}{l}\text { Ley General } \\
\text { de Aguas }\end{array}$ & $\begin{array}{l}\text { Financiación de } \\
\text { partidos Lobby } \\
\text { Captura de ideas > } \\
\text { think tanks } \\
\text { Puertas giratorias }\end{array}$ & $\begin{array}{l}\text {-Explotación de recursos hídricos para } \\
\text { lucro empresarial. } \\
\text {-Sobreexplotación y contaminación de } \\
\text { las fuentes de agua. } \\
\text {-Degradación de los suelos por } \\
\text { deforestación y químicos usados por } \\
\text { distintas actividades productivas. } \\
\text {-Baja disponibilidad de agua por } \\
\text { habitante. } \\
\text {-Acceso desigual al agua. }\end{array}$ \\
\hline
\end{tabular}

Los recursos naturales son el sector en el que la captura y la cultura de privilegios ha estado más presente y donde las élites han defendido con mayor fuerza el mantener el statu quo. ${ }^{64}$ De hecho, datos recientes muestran que en varios países de ALC el índice de renovabilidad de la matriz primaria retrocede, ${ }^{65}$ evidenciando la dificultad de revocar los privilegios de muchas élites que se benefician del extractivismo. De entre todos los recursos naturales, el agua es uno de los más valiosos. Por ello la lucha por su control y uso está en la raíz de muchos conflictos sociales de la región. ${ }^{66}$

En el caso de El Salvador, el agua ha sido históricamente un recurso estratégico de poder para los modelos de desarrollo económico del país basados en la agro-exportación. En la actualidad es también central para el desarrollo agrícola y urbanístico, sobre todo turístico, de El Salvador. Este contexto ha propiciado que su control se haya ido acumulando en las manos de la élite económica de un país en el que cuatro de cada diez personas en las zonas rurales no tienen acceso al agua, el $90 \%$ de las aguas superficiales están contaminadas por desechos industriales, el $99.8 \%$ de la población considera el agua un derecho humano y en el que conviven campos de golf regados con agua potables con zonas donde el $75 \%$ de la población a su alrededor no tiene agua para beber. ${ }^{67}$

La élite económica salvadoreña relacionada con el sector del agua dispone de gran poder, acceso privilegiado e influencia en las decisiones de política pública. Este es un elemento clave para entender la lucha alrededor de la redacción de la Ley de Aguas nacional. La destacada participación de las élites y la formidable presión que han ejercido buscaban influenciar el contenido de esta Ley o, cuanto menos, que no se aprobara una basada en el consenso de todos los actores. En este sentido, se han llevado a cabo varias propuestas para instaurar un ente regulador nacional después que el Foro del Agua presentase en 2006 una primera propuesta de legislación en materia de agua, con poco éxito. Los intereses de la élite, en cambio, sí que estuvieron reflejados en el anteproyecto de la Ley Integral del Agua que, por el contrario, no tenía el respaldo de la sociedad civil.

Esta lucha por el agua se ha convertido en el epicentro de los movimientos sociales del país que reclaman que el acceso al agua sea considerado un derecho humano y que se ponga fin a su mercantilización; un hecho que tan solo beneficia los intereses económicos de una élite y promueve un modelo de desarrollo extractivista.

Para influenciar el proceso legislativo las élites han utilizado diferentes mecanismos, favorecidos por la connivencia existente entre élites política y económica. Destaca, por encima de todos, la financiación de partidos. A pesar de los esfuerzos de las élites, la pugna por influenciar la Ley General de Aguas continúa dado que las propias élites están muy fragmentadas por el contexto político del país. 


\subsection{Cambiarlo todo para que nada cambie}

El análisis de los anteriores casos arroja tres conclusiones principales. Primero, se observa cómo los efectos que generan estas prácticas de captura son parecidos y se pueden resumir en una perpetuación - si no, en un aumento- de los privilegios de una minoría y la negación de derechos para la mayoría.

Segundo, el abanico de sectores que pueden ser objeto de captura es muy amplio, pero la fiscalidad ${ }^{68}$ y los recursos naturales son los de mayor interés para las élites. Territorio, agua y turismo, entre otros, son sectores estratégicos controlados por pocos actores, a menudo vinculados a capital extranjero. ${ }^{69}$ Su control es primordial para las élites tanto de ALC como globales.

Tercero, muchos mecanismos de captura ${ }^{70}$ se repiten en varios casos (ver cuadro 2). Campaña mediática, lobby o puertas giratorias son los más comunes. Otros como el financiamiento de partidos son incluso más relevantes, pero más difíciles de destapar.

\section{Cuadro 2: Mecanismos de captura empleados en los casos analizados}

\begin{tabular}{|c|c|c|c|c|c|c|c|c|}
\hline $\begin{array}{l}\text { Casos/ } \\
\text { Mecanismos }\end{array}$ & $\begin{array}{l}\text { Campaña } \\
\text { mediática }\end{array}$ & $\begin{array}{l}\text { Financiación } \\
\text { de partidos }\end{array}$ & $\begin{array}{l}\text { Recursos } \\
\text { privados }\end{array}$ & $\begin{array}{l}\text { Procedimiento Legislativo } \\
\text { Extraordinario Madrugones }\end{array}$ & Lobby & $\begin{array}{l}\text { Velo } \\
\text { técnico }\end{array}$ & $\begin{array}{l}\text { Puertas } \\
\text { giratorias }\end{array}$ & Judicialización \\
\hline $\begin{array}{l}\text { Perú: la gente } \\
\text { vota, los } \\
\text { recursos } \\
\text { deciden }\end{array}$ & & & & & & & & \\
\hline $\begin{array}{l}\text { República } \\
\text { Dominicana: } \\
\text { turismo a } \\
\text { toda costa }\end{array}$ & & & & & & & & \\
\hline $\begin{array}{l}\text { Argentina: } \\
\text { comunicación } \\
\text { es poder }\end{array}$ & & & & & & & & \\
\hline $\begin{array}{l}\text { El Salvador: } \\
\text { derecho } \\
\text { humano } \\
\text { al agua }\end{array}$ & & & & & & & & \\
\hline
\end{tabular}

Fuente: elaboración propia

En relación a los mecanismos es importante destacar la campaña mediática. El control de la generación opinión y de la agenda pública es de una importancia cabal. Es además uno de los mecanismos más usados por las élites mediante la propiedad de medios o a través de centros de pensamiento. Se generan así debates y narrativas en la sociedad conforme a intereses específicos. Este proceso se vincula con la digitalización, la concentración de medios y, principalmente, el surgimiento de movimientos políticos de tipo iliberal. Estos movimientos tienen gran difusión entre la población por la extensión del uso de la tecnología y las redes sociales para fines políticos. Datos recientes muestran que casi un $30 \%$ de la población consulta diariamente información política a través de Twitter o Facebook. ${ }^{71}$ Estas redes se están convirtiendo en la puerta de entrada a la política de la ciudadanía, en especial de la juventud y, curiosamente, los datos arrojan que cuánto más se usan las redes más crece la insatisfacción con la democracia. 


\section{UNA AGENDA DE TRABAJO A FUTURO PARA RECONFIGURAR EL CONTRATO SOCIAL Y FORTALECER LA DEMOCRACIA}

Para contrarrestar la captura es crucial realizar un análisis que permita entender qué estrategias seguir. Está demostrado que cuanta más presencia tenga un tema en los medios de comunicación, menos posibilidades hay de que las élites incidan en el resultado de la política asociada. ${ }^{72}$ Así, es probable que lo más pragmático sea enfrentar la captura trabajando su impacto en políticas públicas concretas, elevando los casos en medios y partiendo de campañas de sensibilización para conseguir cambios.

En el marco de la coyuntura crítica de la pandemia, existe la oportunidad de repensar los contratos sociales; como está sucediendo en Chile. Los nuevos contratos sociales deben basarse en un cambio profundo en la organización del poder. Esto pasa inevitablemente por hacer frente a las desigualdades políticas; y en este momento, la oportunidad es real. Este debate está en el centro de la agenda tanto de los movimientos sociales como de la sociedad civil organizada e, incluso, de instituciones internacionales como la OCDE.

Este documento quiere plantear agendas de trabajo (ver figura 2 y cuadro 3) - más que recomendaciones concretas que contribuyan a la deliberación sobre el futuro de la democracia y cómo hacer frente a la captura en ALC. ${ }^{73}$ Se quieren responder dos preguntas: ¿qué es necesario para conseguir sociedades más democráticas, en las que los intereses de la mayoría prevalezcan sobre los de las élites? y ¿cómo construir un pacto social que altere la organización del poder y dé sentido y legitimidad a la democracia? En esta línea, cada sociedad debe repensar y acordar su propio contrato social a partir del trabajo conjunto y la creación de consensos entre los diferentes actores que intervienen en el contexto.

Figura 2. Elementos centrales del nuevo pacto social en América Latina y El Caribe

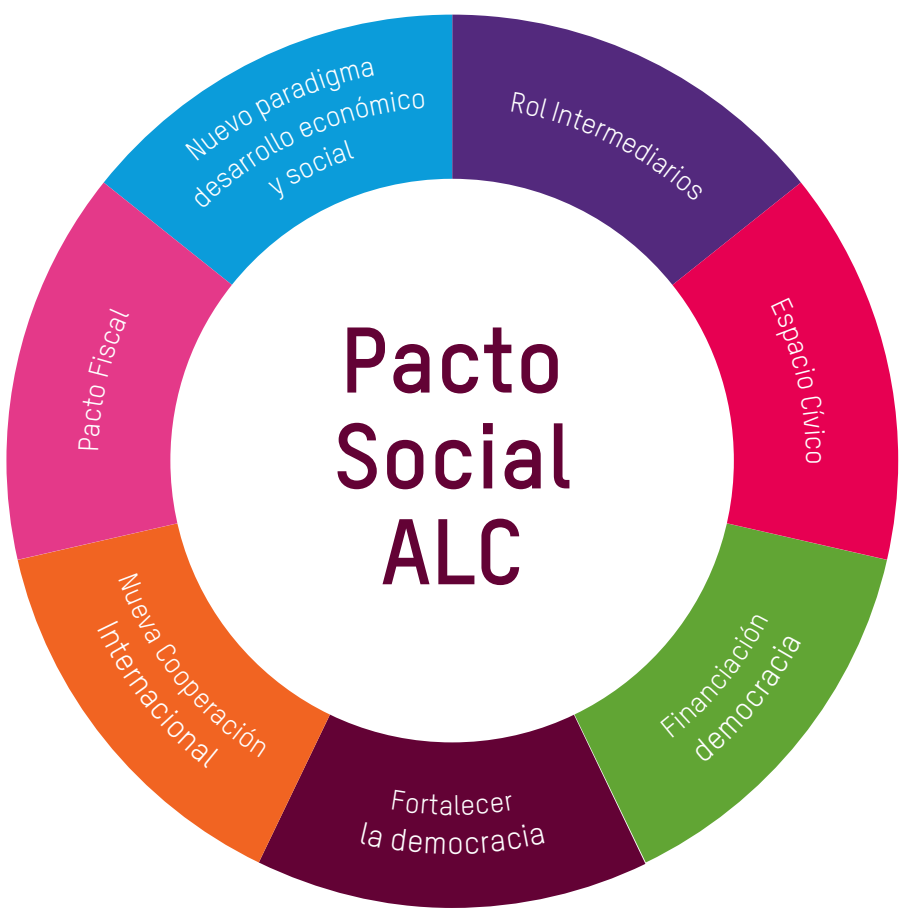

Fuente: elaboración propia 
Cuadro 3. Agendas de trabajo para un nuevo pacto social en LAC

\begin{tabular}{|c|c|c|c|}
\hline Eje & PREGUNTA & IDEA CENTRAL & AGENDA \\
\hline $\begin{array}{l}\text { Fortalecer } \\
\text { la democracia }\end{array}$ & $\begin{array}{l}\text { ¿Cómo recuperar } \\
\text { la democracia } \\
\text { y empoderar a } \\
\text { la ciudadanía? }\end{array}$ & $\begin{array}{l}\text { La democracia está } \\
\text { siendo capturada por } \\
\text { las élites y necesita } \\
\text { ser fortalecida }\end{array}$ & $\begin{array}{l}\text { - Fomentar la participación política y social lespecialmente de } \\
\text { jóvenes y mujeres) } \\
\text { - Priorizar igualdad, justicia social y lucha contra las violencias } \\
\text { - Centralidad de la transparencia y la rendición de cuentas } \\
\text { - Sistemas judiciales libres de captura por intereses políticos y } \\
\text { corporativos }\end{array}$ \\
\hline $\begin{array}{l}\text { Financiación } \\
\text { democracia }\end{array}$ & $\begin{array}{l}\text { ¿Por qué hay } \\
\text { tanto dinero } \\
\text { en la política? } \\
\text { ¿De dónde sale? }\end{array}$ & $\begin{array}{l}\text { Los grupos económicos } \\
\text { invierten muchos } \\
\text { recursos en la política }\end{array}$ & $\begin{array}{l}\text { - Centralidad de la transparencia } \\
\text { - Poner el foco en los grandes intereses detrás de la financiación } \\
\text { - Legislación clara y efectiva }\end{array}$ \\
\hline $\begin{array}{l}\text { Espacio } \\
\text { cívico }\end{array}$ & $\begin{array}{l}\text { ¿Cómo frenar } \\
\text { el cierre de } \\
\text { espacios para el } \\
\text { activismo social? }\end{array}$ & $\begin{array}{l}\text { Las voces alternativas } \\
\text { son silenciadas pese a } \\
\text { tener un protagonismo } \\
\text { en los cambios políticos } \\
\text { y sociales }\end{array}$ & $\begin{array}{l}\text { - Realzar el capital político y social del activismo y de los } \\
\text { movimientos sociales en el cambio } \\
\text { - Proteger el periodismo de investigación y las voces disidentes } \\
\text { - Igualar el espacio urbano al rural } \\
\text { - Evaluar el impacto de la tecnología en la democracia } \\
\text { - Evaluar el impacto de los fundamentalismos religiosos } \\
\text { - Estar atentos a nuevas capturas }\end{array}$ \\
\hline Intermediarios & $\begin{array}{l}\text { ¿Quiénes son, } \\
\text { cómo funcionan } \\
\text { y cómo impactan } \\
\text { a la democracia } \\
\text { estos grupos de } \\
\text { intermediación? }\end{array}$ & $\begin{array}{l}\text { El auge de la consultoría } \\
\text { y la asesoría a gobiernos } \\
\text { y entes públicos } \\
\text { cuestiona qué intereses } \\
\text { son los que se fomentan } \\
\text { y «quién se beneficia». } \\
\text { Opacidad en las } \\
\text { contrataciones públicas. }\end{array}$ & $\begin{array}{l}\text { - Regular las puertas giratorias } \\
\text { - Regular el lobby } \\
\text { - Poner foco en los procesos de contratación pública } \\
\text { - Centralidad de la transparencia } \\
\text { - Fomentar la participación política y social y potenciar la } \\
\text { formación para auditoría social }\end{array}$ \\
\hline $\begin{array}{l}\text { Cooperación } \\
\text { Internacional }\end{array}$ & $\begin{array}{l}\text { ¿A quién beneficia } \\
\text { la cooperación } \\
\text { internacional? }\end{array}$ & $\begin{array}{l}\text { La comunidad } \\
\text { internacional debe } \\
\text { incorporar una } \\
\text { nueva lectura del } \\
\text { poder y evitar que la } \\
\text { cooperación beneficie } \\
\text { prioritariamente a } \\
\text { intereses privados }\end{array}$ & $\begin{array}{l}\text { - Reconocer el rol del activismo y potenciarlo } \\
\text { - Proteger el espacio cívico } \\
\text { - Desarrollar nuevos criterios de análisis en las estrategias de } \\
\text { cooperación } \\
\text { - Definir una agenda de cooperación participativa } \\
\text { - Asegurar la coherencia real de políticas } \\
\text { - Analizar el cui bono (quién se beneficial de la cooperación y su } \\
\text { impacto en relaciones de poder } \\
\text { - Invertir en la participación social y la formación/acción para } \\
\text { auditoría social } \\
\text { - Apoyar la coordinación y cooperación regional anti corrupción }\end{array}$ \\
\hline Pacto Fiscal & $\begin{array}{l}\text { ¿Quién debe } \\
\text { financiar el nuevo } \\
\text { pacto social } \\
\text { y cómo? }\end{array}$ & $\begin{array}{l}\text { Financiar el contrato } \\
\text { social para proveer } \\
\text { servicios públicos } \\
\text { universales requiere } \\
\text { de una movilización de } \\
\text { recursos fuerte para } \\
\text { tener los volúmenes } \\
\text { de inversión social } \\
\text { necesarios. }\end{array}$ & $\begin{array}{l}\text { - Centralidad de los principios de equidad y progresividad para } \\
\text { aumentar la moral fiscal } \\
\text { - Implementar nuevos impuestos adicionales } \\
\text { - Asegurar la transparencia en incentivos y otras medidas } \\
\text { tributarias. } \\
\text { - Actualizar los sistemas tributarios a la economía del s.xxi } \\
\text { (digital, dinámica, de servicios, etc.) } \\
\text { - Impulsar una mayor coordinación fiscal entre gobiernos }\end{array}$ \\
\hline $\begin{array}{l}\text { Nuevo paradigma } \\
\text { de desarrollo } \\
\text { económico y social }\end{array}$ & $\begin{array}{l}\text { ¿Cuáles deben } \\
\text { ser las bases para } \\
\text { un nuevo modelo } \\
\text { de desarrollo? }\end{array}$ & $\begin{array}{l}\text { Ir más allá del } \\
\text { extractivismo forjando } \\
\text { un nuevo modelo } \\
\text { sostenible en el que } \\
\text { las prioridades sociales } \\
\text { estén consensuadas } \\
\text { democráticamente. }\end{array}$ & $\begin{array}{l}\text { - Desmonopolizar la economía. } \\
\text { - Pasar de bienes capturados a bienes públicos. } \\
\text { - Entender los cambios de contexto para identificar nuevos } \\
\text { bienes estratégicos. } \\
\text { - Conseguir consensos amplios sobre las prioridades económicas } \\
\text { y sociales priorizando la ciudadanía. }\end{array}$ \\
\hline
\end{tabular}




\subsection{Fortalecer la democracia}

En los últimos años, la principal causa de protesta en ALC -y en la mayor parte del mundo - ha sido la reivindicación de una democracia real. ${ }^{74}$ Es necesario, por lo tanto, refundar en profundidad la democracia para que pueda cumplir las expectativas de la población y conseguir equilibrar las asimetrías de poder. Solo así se podrá, también, frenar corrientes populistas que erosionan los sistemas democráticos de la región.

El primer mecanismo para revitalizar la democracia es promover que la participación vaya más allá del voto. Se debe construir desde abajo y partiendo de la premisa que no todos los actores están representados en la institucionalidad de una organización o un partido político. Se deben explorar y desarrollar mecanismos y procesos de participación encaminados a entender qué opina y qué temas son los más relevantes para la ciudadanía y ver cómo se pueden incorporar en la agenda pública. Esta participación debe incluir diferentes actores y espacios geográficos (locales y regionales) sin los cuales el contrato social no tiene sentido. Debatir un contrato social es hablar de las bases del presente y, sobre todo, del futuro de una sociedad. Es por ello que la juventud tanto como las minorías raciales y los grupos indígenas son algunos de los actores clave.

Las formas de participación deben adaptarse a los tiempos, para lo cual la flexibilidad es esencial. Los nuevos contratos sociales deben «liberarse» de contextos pasados y, además, hacer una lectura correcta del presente. Ello no es óbice para repetir y poner énfasis en mecanismos que hayan funcionado en el pasado. Es el caso de las consultas populares sobre minería en Colombia. ${ }^{75} \mathrm{El}$ aumento de la participación pasa necesariamente por que las autoridades ofrezcan incentivos a todos los actores y garanticen que todos tienen la misma capacidad de influencia sobre el resultado final.

Segundo, se debe repensar la idea de la representación política. ¿Son los y las representantes políticos los únicos con potestad para tomar la decisión final sobre una política o, por el contrario, existen otros actores a sumar para conseguir consensos sociales más amplios? ¿Son los partidos existentes las únicas opciones o se deben facilitar procesos para introducir listas independientes? Si es así, ¿quiénes son de forma transparente los que participan en esta etapa y con qué legitimidad? En este punto es urgente incorporar en los procesos a las mujeres y las minorías étnicas de forma efectiva y totalmente paritaria para conseguir legitimidad y, de nuevo, buscar formas alternativas de representación. Es el caso de lo acontecido en la Convención Constitucional de Chile, un modelo de paridad y participación de los pueblos originarios a considerar en otros contextos.

En tercer lugar, los Gobiernos deben ser capaces de proveer servicios públicos de calidad financiados con recursos suficientes. Si los sistemas democráticos son incapaces de aumentar su oferta de servicios públicos, es probable que la demanda de los mismos se reduzca puesto que la ciudadanía acudirá a la provisión privada de los mismos. Ello conllevará un aumento de la desigualdad y de los privilegios de aquellos que acceden a servicios de mayor calidad. ${ }^{76}$ Si la democracia es incapaz de proveer igualdad y justicia social - así como protección antes diferentes violencias - su legitimidad seguirá minándose.

En cuarto lugar, la política debe desintitucionalizarse parcialmente y recuperar la esencia de su significado, empoderando a la ciudadanía. La política real va más allá de instituciones y se genera también en las discusiones y debates en otros espacios no formalizados. Esto pasa necesariamente por recuperar, socializar y dignificar la política garantizando el espacio cívico para recuperar el deseo democrático y la participación.

En quinto lugar, los sistemas judiciales muchas veces reproducen y perpetúan la impunidad de los poderosos. Este es un problema estructural en muchos países de la región. Se producen un gran número de casos en los que la justicia no actúa de manera eficaz y cede ante la presión de grupos de poder. Este fenómeno acaba negando el derecho a la justicia a las grandes mayorías y deteriora aún más la confianza de la ciudadanía en las instituciones del Estado. Esta problemática enquista la corrupción al no desincentivarla si no hay respuesta judicial profunda a los diferentes casos que se suceden.

Finalmente, en el contexto actual el elemento central para fortalecer la democracia y poner freno a la captura es la transparencia. Si la democracia no es capaz de demostrar quién gobierna y cómo, qué intereses quieren incidir en el proceso, etc. la democracia pierde validez. De los cinco elementos identificados es quizás el más sencillo de implementar, pero el que requiere de mayor voluntad política para que funcione verdaderamente.

\section{2 ¿Una persona un voto o un dólar un voto?}

El debate relativo a cómo se financia la democracia -incluyendo al crimen organizado - es de gran actualidad. La relación entre dinero, poder y política se ha analizado ampliamente, ${ }^{77}$ pero después de escándalos de financiación ilegal como el de la trama Odebrecht ${ }^{78}$ es más necesario que nunca que esta cuestión sea central en los debates sobre cómo fortalecer la democracia en ALC y en el mundo. El caso de El Salvador es un ejemplo de cómo la financiación de la democracia está en 
el centro de la captura. El proceso chileno de candidaturas independientes a la Convención Constitucional también es un ejemplo de como el dinero no necesariamente debe ser un elemento central en la política. ${ }^{79}$

De nuevo, la transparencia es clave para saber quién financia y cómo las campañas electorales y los partidos. La pregunta a responder siempre es de dónde proviene el dinero. Se debe poner coto al dinero ilegal que entra en la política y que no está bajo el radar, empoderando los sistemas judiciales para investigar los presuntos casos de financiación ilegal. Por algo está demostrado que la política puede convertirse en un mecanismo para el blanqueo del dinero ilegal, principalmente en el ámbito local. .80

Se debe también abrir el debate sobre las exoneraciones fiscales a las donaciones a partidos, campañas y fundaciones y, por consiguiente, preguntarse cómo se puede financiar la democracia y de qué forma puede la ciudadanía participar en este proceso. Aunque pueda parecer banal, determinar de manera transparente y democrática la forma cómo la política se financia es primordial.

La cuestión de la transparencia en la financiación de las políticas debe trasladarse necesariamente a legislaciones concretas. Exceptuando algunos países de Centroamérica, la financiación está altamente regulada en la región. Esto no significa que no existan resquicios (por ejemplo, donaciones en efectivo, que aún están permitidas en la mayoría de países) ni que la implementación de la ley no tenga deficiencias. Hace falta una implementación efectiva de las mismas y reforzar las unidades de investigación judicial que tienen jurisdicción a este respecto.

Finalmente, se debe analizar y revelar por qué alguien financia la política. Hay elementos ideológicos, pero también económicos. En el caso de las empresas que financian a un partido o a un candidato, se les debería vetar el acceso a contratos públicos. De la misma forma, no puede haber representantes del sector privado en los gobiernos si en el pasado o en el presente la empresa o grupo en cuestión ha financiado o asesorado al partido de gobierno, o si ciertos individuos han trabajado en ambas partes (el fenómeno de las puertas giratoria). Esta última cuestión adquiere gran importancia en un contexto de pandemia en el que muchas empresas están recibiendo ayudas públicas. Estos fondos no solo deben estar bien auditados, sino que adicionalmente se deben comprobar si estas empresas han financiado a gobiernos.

\subsection{Abrir espacios a la sociedad civil}

Es probable que la tendencia a cerrar el espacio cívico a determinados actores se agudice. En una región de extractivismo puro como ALC, uno de los grupos más afectados por su presencia en los territorios más ricos en recursos y biodiversidad han sido los y las defensoras del territorio y del medio ambiente, y los movimientos indígenas. A pesar de que la violencia se produce tanto en el ámbito urbano como en el rural, es en este último en el que se desarrollan la mayoría de actividades del extractivismo ligadas, en muchos casos, a capital internacional. Ante la «ola verde» de inversiones que se está produciendo, proteger a estos actores tiene que convertirse en una prioridad.

La sociedad civil no solo está organizada bajo instituciones, sino que también se mueve de manera dinámica desde el activismo y los movimientos sociales. A pesar de que las sociedades en las que hay muchas protestas evidencian problemas profundos, el activismo es un valor que se debe proteger para garantizar la salud democrática de una sociedad. Los movimientos sociales están muy ligados a la juventud urbana de diferentes estratos que no encuentra espacios en la institucionalidad política ni se identifica con los liderazgos existentes de los que desconfía. Sin un mayor espacio para que el activismo y los movimientos sociales se desarrollen, la confianza y apoyo en la democracia caerá cada vez más.

La captura también se manifiesta en los poderes fácticos y confesionales sobre la vida y derechos de las mujeres. El avance político de corrientes ancladas en fundamentalismos religiosos impacta directamente en políticas que restringen derechos, como el bloqueo o la regresividad en el derecho al aborto seguro, legal y gratuito, la diversidad de la familia y otras libertades fundamentales de la ciudadanía.

El periodismo independiente y de investigación es fundamental en un contexto en el que los medios responden cada vez más a intereses empresariales. ${ }^{81}$ Es precisamente este periodismo el que en la mayoría de ocasiones destapa escándalos de corrupción y privilegios de las élites. Es por ello que los gobiernos han de garantizar su protección e independencia ligándolos, por ejemplo, a la protección del poder judicial que puede reforzar el trabajo periodístico de diversas maneras y con distintos recursos.

La captura no solo está presente en políticas concretas, sino que también aparece con fuerza en el campo de las ideas y lo simbólico. La batalla por controlar las narrativas y los canales en los que se difunden son dos de las más importantes. La tecnología es, por tanto, el gran recurso de poder en la actualidad, concentrado en pocas manos y desplegado bajo intereses geopolíticos y empresariales. ${ }^{82}$ No hay dudas del potencial de la expansión de la tecnología; el impacto positivo que puede tener en la vida diaria de las personas y la mejora que puede propiciar en la transparencia y la rendición de cuentas. 
Sin embargo, preocupa su uso como herramienta de vigilancia y que se pueda estar viviendo una «nueva colonización» bajo el mantra de la conexión. ${ }^{83}$

Finalmente, el activismo y la sociedad civil deben ser capaces de pensar disruptivamente para anticipar el futuro. ¿Cómo se llevará a cabo la captura en el nuevo escenario post COVID-19? ¿Qué impacto tendrá la digitalización y la inteligencia artificial en la democracia y las relaciones de poder? ¿Serán las monedas virtuales mecanismos para financiar ilegalmente partidos políticos? ¿Cómo cambian las tecnologías la protesta y el espacio cívico? ¿Cómo operan los fundamentalismos sobre las decisiones políticas que limitan o atentan contra los derechos de las mujeres y poblaciones diversas? ¿Qué influencia tendrá en las élites el cada vez mayor peso de China en la región? Son todas ellas preguntas cuyas respuestas ayudan a prevenir la democracia de ataques orquestados desde diferentes espacios y actores.

\section{4 Los intermediarios}

Los casos de captura y de corrupción pocas veces ponen el foco en los intermediarios o facilitadores de la misma. Generalmente se analiza quién captura o corrompe y quién es capturado o corrompido. Sin embargo, cada vez más se conoce a aquellos actores que asesoran o representan organizaciones en materia fiscal, compra pública, etc. Lo que se denomina como las 'redes de corrupción y de captura'. Afrontar esta cuestión es de gran urgencia.

El foco de atención se puso en estos facilitadores en dos de los escándalos más conocidos de los últimos años. El primero fue LuxLeaks ${ }^{84}$ en el que se reveló como las grandes consultoras asesoraban fiscalmente a empresas en Luxemburgo. El segundo fueron los Panama Papers ${ }^{85}$ en los que el bufet panameño Mossack Fonseca asesoraba jurídicamente a fortunas de todo el mundo sobre cómo evadir impuestos y ocultar a propietarios de empresas pantalla.

Estas dos historias subrayan el poder que tienen estos actores en dictar, implementar y revisar las reglas del juego de varios sectores, así como la necesidad de proteger a los denunciantes - los whistleblowers, en inglés-, ya que son claves para revelar estas mal prácticas. Son estos intermediarios los que en muchas ocasiones asesoran a gobiernos sobre planes nacionales de desarrollo o cambios en diferentes legislaciones. ${ }^{86}$

Urge, por lo tanto, establecer reglas claras y tener información transparente sobre cómo funcionan estos actores intermediarios y hasta qué punto juegan un rol de ideólogos, consultores, auditores e implementadores de políticas públicas. Además, si es conocida su mala praxis en otros contextos, es imperativo limitar su capacidad de actuación.

Los Gobiernos han seguido la tendencia de externalizar los diseños de grandes planes o modelos de desarrollo económico a grupos privados en los que conflictos de intereses y casos de puertas giratorias suelen ser recurrentes. Esta situación es probable que se recrudezca por la crisis de la COVID-19 ante la necesidad de repensar el sector público, el inicio de proyectos de envergadura y la gestión de grandes fondos para la reconstrucción. Esta dinámica ya se está produciendo en algunos países de la UE en la gestión de los fondos Next Generation EU. ${ }^{87}$

\subsection{Una nueva cooperación internacional}

Es imposible pretender que determinadas políticas cumplan el objetivo con el que se diseñaron sin entender cómo funcionan las relaciones de poder formales e informales en un contexto determinado. Para ello hay que saber quién se acaba beneficiando de la política y quién no. Incorporar esta perspectiva en todas las estrategias, intervenciones y políticas de cooperación internacional es de vital importancia para impedir que las políticas orientadas al desarrollo acaben siendo capturadas.

Sin embargo, los propios donantes y la comunidad internacional del desarrollo pueden ser también objeto de captura por parte de, por ejemplo, intereses nacionales o empresariales. La entrada del gran sector privado como un actor central en la cooperación vía mecanismos como el blending ly en las agendas verde y digital) ha sido altamente criticada por la posibilidad de que sus intereses prevalezcan sobre los de las poblaciones receptoras de la ayuda. ${ }^{88}$ Se debe repensar la cooperación partiendo de la concepción de un mundo con un peso cada vez mayor de las temáticas sociales, en el que las agendas del Sur y sus problemáticas sean las que marquen la del Norte (no al revés).

Los donantes podrían, por ejemplo, incorporar indicadores sobre transparencia, contratación pública, financiación de campañas electorales 0 , incluso, el uso que se hace de paraísos fiscales para canalizar los fondos. Igualmente apoyar la coordinación regional en contra de la corrupción. Todo ello con el objetivo de crear «cortafuegos» a la captura y luchar contra la desigualdad en la distribución de poder para que las políticas beneficien realmente a quien deben beneficiar. Es decir, que las estrategias e intervenciones diseñadas creen incentivos para fortalecer la democracia y evitar tanto la captura como el refuerzo de los grupos de poder. Este punto es central en el contexto actual en el que se empiezan a 
diseñar planes de salida a la crisis de la COVID-19. Los donantes tienen una responsabilidad al respecto y, de hecho, ya se han evidenciado malas praxis que han conllevado que fondos internacionales de cooperación hayan beneficiado principalmente a intereses privados. ${ }^{89}$

La cooperación internacional también debe jugar un papel central en la defensa de la sociedad civil y el espacio cívico. El $97 \%$ de los recursos para la sociedad civil en ALC fueron destinados a implementar proyectos y prestar servicios básicos; por el contrario, menos de un $3 \%$ se invirtió en gastos básicos para garantizar el funcionamiento de las organizaciones de la sociedad civil. Asimismo, mientras muchos donantes hablan de la importancia de la democracia y de reconfigurar contratos sociales, poco menos de un $6 \%$ de los recursos para la sociedad civil en ALC se dedica a la promoción del activismo y la incidencia política..$^{90}$

\subsection{Sin impuestos no hay representación (ni servicios públicos de calidad)}

La fiscalidad se ha convertido en una de las reformas más relevantes de la agenda política regional e internacional en los últimos años. Muchas de las experiencias de captura documentadas en la región se originan por la influencia de los grupos de poder para cambiar legislaciones o hacerlas a medida en relación a impuestos.

Las pérdidas que supone para el erario público la evasión y elusión fiscal son ingentes. Ello imposibilita la financiación de servicios públicos que, a su vez, repercute en la desigualdad y en la percepción que se tiene de la democracia como sistema político. Los grupos de poder son los principales beneficiarios de esta dinámica perversa y, además, son los que tienen un mayor acceso a intermediarios que les permiten reducir su contribución fiscal. El caso de los Panama Papers, una vez más, es el más claro. También existe la percepción de que los impuestos no se utilizan para mejorar los servicios públicos, lo que a su vez genera un deterioro de lo que se conoce como moral tributaria (la aceptación de pagar impuestos)..$^{91}$

Es por ello que cobra aún mayor relevancia atajar la incongruencia que supone para el contrato social y la democracia que las élites, que gozan de acceso privilegiado al poder político, sean las que evitan en mayor medida pagar impuestos. El contrato social debe pasar inevitablemente por abordar la cuestión fiscal como un elemento clave para hacer que la democracia funcione con efectividad y sea el sistema que provea servicios públicos de calidad a la ciudadanía.

Uno de los impuestos más batallados en la actualidad está siendo el de la riqueza, pero no es el único. El impacto de la crisis de la COVID-19 ha abierto un proceso de concesión de exenciones fiscales extraordinarias en la que los grupos de poder expresaron sus preferencias. En un contexto de crecimiento a toda costa, se debe prestar especial atención en los nuevos privilegios tributarios que van a trasladarse desde los diferentes lobbies a los gobiernos de la región.

Para tener un contrato social legitimado y respetado es básico un pacto fiscal que permita al Estado redistribuir y financiar los servicios públicos. ALC adolece de no tener estos pactos fiscales, con la repercusión que en los contratos sociales conlleva. La crisis de la COVID-19 es también una oportunidad para repensar la idea y contenido del pacto fiscal. Este paso será necesario afrontarlo en todos los países de la región en los que déficits fiscales y deuda pública se han disparado.

\subsection{Un nuevo paradigma económico y social: de bienes capturados a bienes públicos}

América Latina necesita repensar el modelo económico y social que va asociado a grandes privilegios de grupos de poder para reconfigurar el contrato social. No solo se trata de intentar construir alternativas al extractivismo, sino también de desmonopolizar la economía orientándola hacia sectores más respetuosos con el medio ambiente y los objetivos sociales.

Este nuevo paradigma debe pasar inevitablemente por convertir los bienes capturados en bienes públicos utilizando políticas que protejan estos bienes estratégicos de su explotación en términos únicamente de mercado. Esto implica que la toma de decisiones respecto a su uso debe pasar necesariamente por un espacio de diálogo social con la población y los actores involucrados para poder tener en cuenta los diferentes intereses en juego.

La crisis climática y de acceso a recursos naturales básicos está relacionada con la captura por la presión de las élites para expandir el control y el beneficio sobre los recursos naturales que son, a su vez, estratégicos. Pero estos recursos naturales no se limitan únicamente a la minería. Lo son también el turismo (como en el caso de República Dominicana), el agua (como en El Salvador) o el territorio, entre otros.

El agua es, precisamente, uno de los recursos naturales que mejor ejemplifica la acumulación de privilegios en detrimento de derechos. En Chile, por ejemplo, el agua está privatizada y el acceso a la misma en regiones alejadas de la capital es precario. Otros recursos preciados por élites son los relacionados con la agroindustria. Brasil y Bolivia son dos ejemplos claros de cómo las élites económicas se han alineado con las élites políticas para capturar la explotación del territorio 
en su propio beneficio. ${ }^{92}$ Se necesita cambiar el paradigma y conseguir que este tipo de recursos se conviertan en bienes públicos y se defiendan a partir de una lógica integral de los mismos, lo que implica considerar que por su naturaleza y uso tienen efectos en múltiples ámbitos, y son básicos para el ser humano.

Finalmente, también deben ser considerados bienes públicos la tecnología, la información y las vacunas en el contexto actual. Se tiene que ampliar, por lo tanto, la noción de bienes públicos para poder proteger aquellos recursos estratégicos para el desarrollo de una sociedad. Solo así se podrá poner límites al poder corporativo y construir un nuevo paradigma económico y social.

\section{CONCLUSIONES}

Este documento muestra cómo la relación entre desigualdad, poder y dinero acaba permeando la política y los imaginarios sociales a través de la captura. Los casos analizados ilustran cómo la captura llevada a cabo por determinadas élites de ALC tiene un impacto en la vida diaria de millones de personas y afecta a sectores diferentes de la sociedad. La captura, como se muestra, está muy arraigada en la región. Se trata de un fenómeno que ha sido central en la deslegitimación de la democracia, el recrudecimiento de las desigualdades y el refuerzo de relaciones de poder asimétricas. En un momento como el actual, en el que los debates sobre la recuperación de la región se suceden, las élites están aprovechando su posición para ejercer influencia y no quedar fuera del reparto de recursos, haciendo prevalecer sus intereses. ${ }^{93}$ En la región donde la democracia pierde más apoyos, las élites refuerzan su poder.

ALC solo saldrá de la crisis actual a través de una reconfiguración del contrato social que conlleve modificar la actual organización del poder. El contrato social y la democracia se deben fortalecer poniendo las desigualdades y los derechos económicos y sociales en el centro de la agenda. La clase política también debe rendir cuenta de sus actos, y encontrar formas de aumentar el deseo de democracia entre la ciudadanía. Promover la transparencia, atraer a la juventud y a las mujeres, y ampliar espacios participativos más allá de los institucionales son todos ellos mecanismos esenciales para conseguirlo.

Es tarea de organizaciones como OXFAM no dejar escapar la oportunidad que el momento actual brinda. Es de urgente necesidad que se abran debates, se creen espacios y se influya desde la base para cambiar las formas en las que se distribuye el poder. En paralelo, los estados y los Gobiernos deben cambiar su relación con la ciudadanía, empezando por aceptar la movilización social como necesaria. La juventud y la calle piden cambios. Para OXFAM solo vale promover una agenda de cambios que conduzca a construir consensos con todos los actores para rehacer el contrato social. Únicamente con una democracia libre de captura se podrá hacer frente a la desigualdad. 


\section{NOTAS}

${ }^{1}$ Ver IDEA. (2019). IDEA The global state of democracy 2019. Addressing ills, reviving the promise. Estocolmo: IDEA. https://www.idea.int/publications/ catalogue/global-state-of-democracy-2019; R.G. Wilkinson y K. Pickettt. (2009). The Spirit Level: why more equal societies almost always do better. Londres: Allen Lane.

${ }^{2}$ https://policy-practice.oxfam.org/resources/democracias-capturadas-el-gobierno-de-unos-pocos-620600/

${ }^{3}$ Ver: Leopoldo Fergusson. (2016). Estado y corrupción. https://www.youtube.com/watch?v=N1IwhvMWhOY

${ }^{4}$ The Economist Intelligence Unit. (2021). Democracy Index 2020. In sickness and in health?

${ }^{5}$ https://theconversation.com/la-militarizacion-en-america-latina-en-tiempos-de-covid-19-154781

${ }^{6}$ La definición de democracia (real) de Rancière afirma que «es una demanda no solo de una mejor gobernanza y una representación más amplia, pero también de participación universal directa y una sociedad en la que los principios de libertad e igualdad no sólo se encuentran en las leyes e instituciones, sino en la vida diaria» ver J. Rancière (2006). Hatred of democracy. Londres: Verso; o Wolin que la define como «el proceso en el cual el pueblo (demos) lucha por sus derechos, logra ganarlos, sostenerlos y en el proceso adquiere experiencia de lo político, sus consecuencias de su ejercicio y la lucha por el bienestar común, en medio de las diferencias culturales y las desigualdades socioeconómicas» ver S.S. Wolin (1996). Review: the liberal / democratic divide. On Rawl's Political Liberalism. Political Theory, vol. 24, 1. P.97-119.

${ }^{7}$ Ver: OECD. (2017). Preventing policy capture: integrity in public decision making. OECD Publishing: Paris; John Crabtree y Francisco Durand. (2017). Perú: élites del poder y captura política. Lima, Perú: Red para el desarrollo de las ciencias sociales del Perú.

${ }^{8}$ Sin embargo, ello no niega que pueda existir un carácter más estructural a nivel de todas las instituciones, como se identifica el caso de Guatemala donde se habla de Captura del Estado. Ver informe CICIG al respecto: https://www.cicig.org/wp-content/uploads/2019/08/Informe Captura Estado 2019.pdf

${ }^{9}$ Daron Acemoglu et al. (2015). Democracy, redistribution and inequality. Handbook of income distribution, Volume 2B.

${ }^{10}$ The Economist. (2021).

${ }^{11}$ R.S. Foa et al. (2020). The global satisfaction with democracy report 2020. Cambridge UK: Center for the future of democracy. https:// www.cam.ac.uk/ system/files/report2020 003.pdf

${ }^{12}$ R.S. Foa et al. (2020). Youth and Satisfaction with Democracy: reversing the democratic discontent? Cambridge UK: Center for the future of democracy. https://www.cam.ac.uk/system/files/youth and satisfaction with democracy.pdf

${ }^{13} \mathrm{http}$ // agendapublica.elpais.com/oportunidad-para-construir-una-nueva-decada-en-america-latina-y-el-caribe/

${ }^{14}$ Elizabeth J. Zechmeister, y Noam Lupu (eds). (2019). Americas Barometer Pulse of Democracy. Nashville TN: LAPOP. https://www.vanderbilt.edu/lapop/ ab2018/2018-19 AmericasBarometer Regional Report 10.13.19.pdf

${ }^{15}$ Corporación Latinobarómetro. (2018). Latinobarómetro Informe 2018.

${ }^{16}$ Coralie Pring y Jon Vrushi. (2019). Global corruption barometer Latin America \& the Caribbean 2019. Citizen's views and experiences of corruption. Transparencia Internacional.

${ }^{17}$ IPSOS (2020). La crisis del coronavirus: Encuesta a líderes de opinión de Latinoamérica. https://www.ipsos.com/sites/default/files/ct/news/documents/2020-09/la crisis del coronavirus- encuesta a lideres de opinion de latinoamerica 0.pdf

${ }^{18}$ Para esta sección se utilizan datos de desigualdad en base al índice GINI de ingreso. Reconociendo sus debilidades metodológicas y de alcance (como el subregistro de los deciles más altos), esta es la medida estándar que permite medir la desigualdad de ingreso a lo largo de los años. En este sentido, pese a que el GINI muestra una reducción de la desigualdad en Latinoamérica, la concentración de la riqueza ha aumentado sin parar. De forma análoga, otros indicadores han ido empeorando.

${ }^{19}$ Algunos autores también ligan esta desafección con el poco crecimiento económico y la falta de oportunidades ligado a ello. Ver: http://centroestudiosinternacionales.uc.cl/medios/3739-los-desafios-de-america-latina-desigualdad-protesta-social-y-populismo

${ }^{20}$ Matías Busso y Julián Messina. (2020). La crisis de la desigualdad: América Latina y el Caribe en la encrucijada. BID. https://www.iadb.org/es/noticias/desigualdades-empeoran-vulnerabilidad-de-america-latina-y-caribe-ante-crisis-estudio-bid

${ }^{21}$ En Colombia son necesarias casi doce generaciones para que una recién nacida del decil más pobre alcance el ingreso medio del país. Ver: OCDE. (2018). A broken social elevator? How to promote social mobility. https://www.oecd-ilibrary.org/social-issues-migration-health/a-broken-social-elevator-how-to-promote-social-mobility/sticky-floor-at-the-bottom-and-sticky-ceiling-at-the-top 9789264301085-graph88-en

22 Ver: Acemoglu et al. (2015).

${ }^{23}$ Hay excepciones como El Salvador donde es probable que la violencia y la sensación de inseguridad sean factores importantes a tener en cuenta. Según un estudio de la cultura política y la democracia en el país, en 2018 «un $61.9 \%$ de la población de El Salvador percibe la seguridad como el problema más grave que está enfrentando el país». Ver: LAPOP et al. (2019). Cultura política de la democracia en El Salvador y en las Américas $2018 / 2019$

${ }^{24}$ Desigualdad de ingreso medida por GINI (2014-2019). Datos para Argentina a nivel urbano. Nicaragua y Guatemala solo tienen disponibles datos para 2014. Apoyo a la democracia (2013-2018) medida en base a adhesión a la afirmación «La democracia es preferible a cualquier otra forma de gobierno». Ver: CEPAL. (2021). Panorama Social de América Latina y el Caribe 2021. CEPAL: Santiago de Chile. Y Corporación Latinobarómetro (2018). Informe 2018.

${ }^{25}$ Ver, por ejemplo, el caso de España con uno de los mayores descensos de la confianza y apoyo a la democracia, con una desigualdad baja en comparación con los países de ALC.

${ }^{26} \mathrm{~A}$ pesar de ello, ya se ha dejado clara la relación que existe entre desigualdad y captura.

${ }^{27}$ Para poder observar la mayor capacidad de ciertos grupos para influenciar la política en su poder se utiliza el indicador de VDem Igualdad de poder político por posición socioeconómica. Datos del Social Progress Index 2021 que utiliza el mencionado indicador de VDEM. Escala de 0 a 4 donde '0' equivale a «Los ricos tienen el monopolio sobre el poder político y los segmentos pobres y medios de la sociedad casi no tienen influencia»; ' 1 ' «Los ricos tienen una posición dominante sobre el poder político»; ' 2 ' «Los ricos tienen una gran influencia sobre el poder político»; ' 3 ' «Los ricos tienen más poder que otros pero pobres y clases medias tienen casi el mismo poder de influencia»; $y$ ' 4 ' «Los ricos no tienen más poder que otras clases socioeconómicas de la sociedad». Ver: https://www.v-dem.net/en/data/data-version-10/ y https://www.socialprogress.org/

${ }^{28}$ Ver: https://www.economist.com/the-americas/2021/04/03/the-influence-of-central-american-dynasties-is-ebbing

${ }^{29}$ Ver: Isabel Ortiz et al. (2021). World Protests 2006-2020. FES-NY y IPD: New York. A publicar en los próximos meses. 
30 Ver el caso de República Dominicana: Anselmo Muñiz et al. (2018). Imaginar el futuro. Ciudadanía y democracia en la cultura política dominicana. Instituto de Investigación para el Desarrollo, Fundación FES y OXFAM. http://library.fes.de/pdf-files/bueros/fescaribe/14836.pdf

31 Ver los diferentes informes anuales de CIVICUS: https://monitor.civicus.org/

32 https://www.aa.com.tr/es/mundo/ong-registra-84-asesinatos-contra-defensoras-de-derechos-humanos-en-siete-a\%C3\%Blos-en-colombia/1979832

33 Ver: https://www.ipsnews.net/2020/10/amid-covid-19-health-civic-freedoms/

${ }^{34}$ Ver: CIVICUS (2020). https://www.civicus.org/index.php/media-resources/media-releases/4787-11-countries-downgraded-in-new-global-reporton-civic-freedoms

${ }^{35}$ Ver: http://centroestudiosinternacionales.uc.cl/medios/3739-los-desafios-de-america-latina-desigualdad-protesta-social-y-populismo y https:// www.bbc.com/mundo/noticias-america-latina-53181485

36 https://www.nytimes.com/es/2020/01/22/espanol/opinion/elites-america-latina.html

${ }^{37}$ Ferran Izquierdo Brichs y John Etherington. (2018). Poder global. Una mirada desde la sociología del poder. Edicions Bellaterra: Barcelona.

38 Ver casos del periodismo: https://forbiddenstories.org/es/case/green-blood/

39 The Economist. (2021).

40 Ver: Julián Cárdenas et al. (2020). Élites empresariales y desigualdad en tiempos de pandemia en América Latina.

41 https://www.godominicanrepublic.com/es/news-posts/actual/ministro-de-turismo-presenta-avances-del-plan-de-recuperacion-turistica/

42 Cárdenas et al. (2020).

43 https://ojo-publico.com/especiales/buscador-companias-beneficiadas-reactiva-peru/

44 Utilizando el lobby como instrumento central empresas energéticas, del plástico y del sector aeronáutico han conseguido retrasar estándares ambientales en la UE, garantizar su supervivencia en EE.UU. e, incluso, conseguir fondos del Banco Central Europeo vía la compra masiva de bonos empresariales. Ver: Greenpeace. (2020). Coronavirus recovery. A free ride for polluters. https://www.greenpeace.org/eu-unit/issues/democracy-europe/3908/three-tests-eu-covid19-recovery-plan/ ; Global Witness. (2020). Occidental's lobbying pays-off as it stands to benefit from coronavirus bailout. https://www.globalwitness.org/en/campaigns/oil-gas-and-mining/occidental-lobbying-pays-off-stands-to-benefit-from-coronavirus-bailout/; https://odg.cat/es/mapas/empresas-bce-pepp/

${ }^{45}$ https://www.oxfam.org/en/cashing-coronavirus-crisis-5-ways-which-corporations-are-exacerbating-inequality

46 https://www.publico.es/economia/industria-farmaceutica-negocio-billon-dolares-engorda-gracias-coronavirus.html

${ }^{47}$ https://www.thebureauinvestigates.com/stories/2021-02-23/held-to-ransom-pfizer-demands-governments-gamble-with-state-assets-to-secure-vaccine-deal

${ }^{48}$ Ver: P.M. Siavelis. (2000). The President and Congress in Post-Authoritarian Chile. Institutional constraints to democratic consolidation. University Park: Pennsylvania State University Press.

${ }^{49}$ Roberto Gargarella. (2020). Diez puntos sobre el cambio constitucional en Chile. En NUSO 285 enero-febrero. https://nuso.org/articulo/diez-puntos-sobre-el-cambio-constitucional-en-chile/

${ }^{50}$ Ver el caso de la reforma fiscal de 2014. Rosa María Cañete. (2018). Democracias capturadas. El gobierno de unos pocos. Oxfam Internacional. https:// oi-files-d8-prod.s3.eu-west-2.amazonaws.com/s3fs-public/file attachments/democracias capturadas resumen.pdf

${ }^{51}$ Ver: Nora Lustig. (2020). Desigualdad y descontento social en América Latina. En NUSO 286 Marzo-abril. https://nuso.org/articulo/desigualdad-y-descontento-social-en-america-latina/; y https://www.bbc.com/mundo/noticias-56247275

52 Ver: https://www.bbc.com/mundo/noticias-america-latina-54630310

53 https://www.clacso.org/elites-captura-del-estado-y-desigualdad-en-america-latina-y-el-caribe/

${ }^{54}$ Francisco Durand y Emilio Salcedo. (2020). El dinero de la democracia. Quién financia a los partidos políticos. Oxfam en Perú y Universidad Pontificia Católica del Perú. https://www.fondoeditorial.pucp.edu.pe/ciencia-politica/1136-el-dinero-de-la-democracia-quien-financia-los-partidos-politicos.html

${ }^{55}$ Esta situación se podría estar dando actualmente en Perú ante el auge del candidato Pedro Castillo frente a Keiko Fujimori. Ver: https://www.americaeconomia.com/izquierdista-castillo-asegura-que-no-permitira-que-grandes-empresas-sigan-saqueando-peru

56 http://www.otramirada.pe/aportes-econ\%C3\%B3micos-empresarios-y-campa\%C3\%Blas-electorales

57 https://idehpucp.pucp.edu.pe/entrevistas/mauricio-zavaleta-peruanos-por-el-kambio-es-un-grupo-con-espiritu-tecnocratico-antes-que-politico/y https://www.americaeconomia.com/politica-sociedad/politica/jorge-barata-revelo-que-financio-en-peru-las-campanas-de-kuczynski-keiko ; https://gestion.pe/peru/politica/ppk-mi-campana-presidencial-hubo-plata-sucia-228458-noticia/

${ }^{58}$ Keiko Fujimori es la hija de Alberto Fujimori y está denunciada por corrupción en relación, entre otros, con el caso Odebrecht. Ver: https://elcomercio. pe/politica/keiko-fujimori-cronologia-de-la-investigacion-por-el-caso-odebrecht-jose-domingo-perez-poder-judicial-fuerza-popular-noticia/

${ }^{59}$ Gilda Masiell Solano Cabrera. (2020). Turismo a toda costa en la República Dominicana. La captura de los incentivos fiscales: sus actores y recursos de poder. http://library.fes.de/pdf-files/bueros/fescaribe/16683.pdf

60 Ver: CEPAL y OXFAM. (2019). Los incentivos fiscales a las empresas en América Latina y el Caribe. https://www.cepal.org/es/publicaciones/44787-incentivos-fiscales-empresas-america-latina-caribe

${ }^{61}$ Documento CEPAL sobre la crisis del turismo: https://www.cepal.org/es/publicaciones/45770-medidas-recuperacion-sector-turistico-america-latina-caribe-oportunidad-promover

62 https://www.arecoa.com/hoteles/2014/12/05/las-10-familias-espanolas-que-dominan-la-hoteleria-dominicana/

63 https://www.clacso.org/la-captura-de-la-ley-de-servicios-de-comunicacion-audiovisual-las-elites-mediaticas-en-el-sxxi/

${ }^{64}$ Ver el caso de Chile: https://www.bbc.com/mundo/noticias-51622758

${ }^{65}$ El índice de renovabilidad mide los cambios en la matriz energética en relación a energía de origen fósil o renovable. CEPAL. (2020). Construir un nuevo futuro: una recuperación transformadora con igualdad y sostenibilidad. Santiago de Chile: CEPAL. https://www.cepal.org/es/publicaciones/46227-construir-un-nuevo-futuro-recuperacion-transformadora-igualdad-sostenibilidad

${ }^{66}$ Ver los casos de Costa Rica, Paraguay, Perú, México y Brasil en: Universidad de Jaén. (2020). Gestión del agua y relaciones de poder en América Latina. Número 15.https://doi.org/10.17561/at.15

${ }^{67}$ Déborah Itríago. (2020). El Salvador: agua, élites y poder. Oxfam en El Salvador. https://lac.oxfam.org/latest/policy-paper/informe-\%E2\%80\%9Cel-salvador-agua-\%C3\%A9lites-y-poder\%E2\%80\%9D; Instituto Universitario de Opinión Pública. (2020). La población salvadoreña opina sobre el derecho al agua. Boletín de prensa XXXIV año 3. 
68 Ver: Cañete. (2018).

${ }^{69}$ Ver: Erika Castillo et al. (2020). Determinantes de la inversión extranjera directa en Latinoamérica (2000-2017). Revista Espacios Vol. 41 (50)

70 Que estos sean los más visibles no implica que sea los únicos que utilicen.

${ }^{71}$ Americas Barometer (2019).

72 Ver: https://blogs.lse.ac.uk/europpblog/2020/08/28/how-wealthy-lobby-groups-benefit-from-a-silent-media/\#Author

${ }^{73}$ Estas propuestas no necesariamente tienen relación directa con los casos presentados anteriormente.

${ }^{74}$ Ortiz et al. (2021).

${ }^{75}$ Estas consultas se empezaron en 2016, pero la Corte Constitucional las vetó para las causas mineras en 2018 . Ver: https://www.larepublica.co/ especiales/minas-y-energia-marzo-2019/comunidades-votaron-en-10-consultas-populares-mineras-desde-el-2013-2842036

${ }^{76}$ Es lo que se conoce como la trampa de los bienes públicos. Ver: Leopoldo Fergusson. (2015). La trampa de los bienes públicos TED x Youth. https:// www.youtube.com/watch?v=qXEz XT-qiA

77 Ver: David Kupferschmidt. (2009). Illicit political Finance and State Capture. (IDEA); y OEA. (2011). Política, dinero y poder. Un dilema para las democracias de América Latina.

${ }^{78}$ Ver: Francisco Durand. (2018). Odebrecht la empresa que capturaba gobiernos. OXFAM.

${ }^{79}$ Ver: https: / / convoca.pe/agenda-propia/chile-las-campanas-millonarias-de-la-eleccion-de-la-asamblea-constituyente-que-fueron?fbclid=IwARIpa e 00Qjr4lQXubvZlhePuJTmPaWeOiT cRoDYVzb-tXJZTkzUT33VE

${ }^{80}$ Ver: Organización Estados Americanos, Secretaría General. (2011). Política, dinero y poder. Un dilema para las democracias de las Américas.

81 Ver: Mariana Rodríguez y Elizabeth J. Zechmeister. (2018). Media pluralism, public trust, and democracy: new evidence from Latina America and the Caribbean. LAPOP. https://www.vanderbilt.edu/lapop/docs/CIMA-Media-Perceptions-in-the-Americas web 150ppi.pdf

82 Ver: https://agendapublica.es/polos-tecnologicos-geopolitica-en-movimiento/

${ }^{83}$ Ver: Renata Ávila Pinto. (2018). Digital sovereignity or digital colonialism? International Journal on Human Rights. https://sur.conectas.org/en/digital-sovereignty-or-digital-colonialism/

84 https://www.icij.org/investigations/luxembourg-leaks/

85 https://www.icij.org/investigations/panama-papers/

${ }^{86}$ Ver por ejemplo el caso de Guatemala y la asesoría de McKinsey para el plan Guatemala no se detiene: https://lahora.gt/presidente-giammattei-presenta-plan-mckinsey-a-la-comunidad-internacional/

${ }^{87}$ Ver el caso de Italia: https:// www.bloomberg.com/news/articles/2021-03-06/italy-hires-mckinsey-for-eu-recovery-funds-upsetting-lawmakers y España: https://www.elconfidencial.com/empresas/2020-09-18/fondo-recuperacion-big-four-espana-moncloa 2753048/

${ }^{88}$ Hay quien habla de un nuevo Wall Street Consensus al respecto, principalmente en la aplicación de Alianzas Público Privadas. Ver: UCL. (2021). Wall Street Consensus: the pandemic turn to Green conditionality. https://www.youtube.com/results? search query=daniela+gabor+wall+street+con$\underline{\text { sensus }}$

${ }^{89}$ Ver: Ourania Dimakou et al. (2020). Never let a pandemic go to waste. How the World Bank's COVID-19 response is prioritizing the private sector. EURODAD y SOAS

90 Ver: https://www.civicus.org/index.php/es/acceso-a-recursos-para-las-organizaciones-de-la-sociedad-civil-en-america-latina

${ }^{91}$ OECD/CAF/ECLAC. (2018). Latin American Economic Outlook 2018: Rethinking Institutions for Development, OECD Publishing: Paris. https://doi. org/10.1787/leo-2018-en

92 Ver: Juan Carlos Salas Acarapi. (2017). Desigualdad en el acceso, la propiedad, la tenencia y la distribución de la tierra en: Inclusión social en Bolivia: Avances y desafíos (2006-2014). Política pública, estructura económica y tierra. Vicepresidencia del Estado Plurinacional de Bolivia. OXFAM: La Paz.

93 Ver: Julián Cárdenas et al. (2020). 


\section{Documentos de Trabajo de Oxfam}

El objetivo de los Documentos de Trabajo de Oxfam es contribuir al debate público y suscitar el intercambio de ideas sobre cuestiones de política humanitaria y de desarrollo. Se trata de documentos "vivos", "en evolución", que no constituyen necesariamente un trabajo definitivo ni reflejan las posturas políticas de Oxfam. Las opiniones y recomendaciones aportadas son de los autores y no reflejan necesariamente las de Oxfam.

Este documento ha sido escrito por Hernán Saenz Cortés y gestionado por Pablo Andrés Rivero. Oxfam agradece la colaboración de Andrea Costafreda, Susana Ruiz, Armando Mendoza y Carlos Botella. El autor expresa su agradecimiento a una serie de expertas y expertos que proporcionaron asistencia: Diego Sánchez-Ancochea, Julián Cárdenas, Francisco Durand, Alicia Rocha-Menocal, Elisa Mougin, Déborah Itríago y Juan Vázquez Zamora. La revisión de la edición del documento ha estado a cargo de Ignacio Iturralde.

Para más información o para aportar comentarios a este documento, póngase en contacto con el autor Hernan.cortes@oxfam.org

\section{(c) Oxfam Internacional julio 2021}

Esta publicación está sujeta a copyright, pero el texto puede ser utilizado libremente para la incidencia política y campañas, así como en el ámbito de la educación y de la investigación, siempre y cuando se indique la fuente de forma completa. El titular del copyright solicita que cualquier uso de su obra le sea comunicado con el objeto de evaluar su impacto. La reproducción del texto en otras circunstancias, o su uso en otras publicaciones, así como en traducciones o adaptaciones, podrá hacerse después de haber obtenido permiso y puede requerir el pago de una tasa. Debe ponerse en contacto con policyandpractice@oxfam.org.uk.

La información en esta publicación es correcta en el momento de enviarse a imprenta.

Publicado por Oxfam GB para Oxfam Internacional con ISBN 978-1-78748-775-8 en julio 2021.

DOI: 10.21201/2021.7758 Oxfam GB, Oxfam House, John Smith Drive, Cowley, Oxford, OX4 2JY, Reino Unido.

\section{OXFAM}

Oxfam es una confederación internacional de 21 organizaciones con sus aliadas y socias, que alcanza a millones de personas en el mundo. Juntas enfrentos las desigualdades para acabar con la pobreza y las injusticias, ahora y en el largo plazo - para un futuro igual para todas. Por favor contacte cualquiera de las organizaciones para más información o visite www.oxfam.org

Oxfam Alemania (www.oxfam.de)

Oxfam América (www.oxfamamerica.org)

Oxfam Aotearoa (www.oxfam.org.nz)

Oxfam Australia (www.oxfam.org.au)

Oxfam-en-Bélgica (www.oxfamsol.be)

Oxfam Brasil (www.oxfam.org.br)

Oxfam Oxfam Canadá (www.oxfam.ca)

Oxfam Colombia (lac.oxfam.org/countries/colombial)

Oxfam Francia (www.oxfamfrance.org)

Oxfam GB (www.oxfam.org.uk)

Oxfam Hong Kong (www.oxfam.org.hk)
Oxfam IBIS (Dinamarca) (www.oxfamibis.dk)

Oxfam India (www.oxfamindia.org)

Oxfam Intermón (España) (www.oxfamintermon.org)

Oxfam Irlanda (www.oxfamireland.org)

Oxfam Italia (www.oxfamitalia.org)

Oxfam México (www.oxfammexico.org)

Oxfam Novib (Países Bajos) (www.oxfamnovib.nl)

Oxfam Quebec (www.oxfam.qc.ca)

Oxfam Sudáfrica (www.oxfam.org.za)

KEDV (www.kedv.org.tr/) 